ARTICLE

https://doi.org/10.1038/s41467-019-11843-0

\title{
Non-classical tissue monocytes and two functionally distinct populations of interstitial macrophages populate the mouse lung
}

Joey Schyns 1,2,3, Qiang Bai (10 1,3, Cecilia Ruscitti1,3, Coraline Radermecker ${ }^{1,3}$, Sebastiaan De Schepper ${ }^{4}$, Svetoslav Chakarov (10 5 , Frédéric Farnir (10) 3,6, Dimitri Pirottin 1,3, Florent Ginhoux (1D 5,7, Guy Boeckxstaens ${ }^{4}$, Fabrice Bureau2,3,8 \& Thomas Marichal (10) 1,2,3,8

Resident tissue macrophages (RTM) can fulfill various tasks during development, homeostasis, inflammation and repair. In the lung, non-alveolar RTM, called interstitial macrophages (IM), importantly contribute to tissue homeostasis but remain little characterized. Here we show, using single-cell RNA-sequencing (scRNA-seq), two phenotypically distinct subpopulations of long-lived monocyte-derived IM, i.e. CD206 ${ }^{+}$and CD206-IM, as well as a discrete population of extravasating $\mathrm{CD} 64^{+} \mathrm{CD} 16.2^{+}$monocytes. $\mathrm{CD} 206^{+} \mathrm{IM}$ are peribronchial self-maintaining RTM that constitutively produce high levels of chemokines and immunosuppressive cytokines. Conversely, CD206-IM preferentially populate the alveolar interstitium and exhibit features of antigen-presenting cells. In addition, our data support that CD64 ${ }^{+}$CD16.2 $2^{+}$monocytes arise from intravascular Ly-6Clo patrolling monocytes that enter the tissue at steady-state to become putative precursors of CD206-IM. This study expands our knowledge about the complexity of lung IM and reveals an ontogenic pathway for one IM subset, an important step for elaborating future macrophage-targeted therapies.

\footnotetext{
${ }^{1}$ Laboratory of Immunophysiology, GIGA Institute, Liège University, Avenue de I'Hôpital 11, B34, 4000 Liège, Belgium. ${ }^{2}$ Laboratory of Cellular and Molecular Immunology, GIGA Institute, Liège University, Avenue de I'Hôpital 11, B34, 4000 Liège, Belgium. ${ }^{3}$ Faculty of Veterinary Medicine, Liège University, Boulevard de Colonster 20, 4000 Liège, Belgium. ${ }^{4}$ Translational Research Center for Gastrointestinal Disorders, Department of Chronic Diseases, Metabolism and Ageing, KU Leuven, Herestraat 49, O\&N1, Box 701, 3000 Leuven, Belgium. ${ }^{5}$ Singapore Immunology Network (SIgN), A*STAR, Biomedical Grove 8 a, 138648 Singapore, Singapore. ${ }^{6}$ FARAH Institute, Liège University, Boulevard de Colonster 20, 4000 Liège, Belgium. ${ }^{7}$ Shangai Institute of Immunology, Shanghai JiaoTong University School of Medicine, South Chongqing Road 280, 200002 Shanghai, China. ${ }^{8}$ WELBIO, Walloon Excellence in Life Sciences and Biotechnology, Wallonia, Belgium. Correspondence and requests for materials should be addressed to T.M. (email: t.marichal@uliege.be)
} 
$\mathrm{R}$ esident tissue macrophages (RTM) are present in most mammalian tissues. Historically known for their roles in host defense and clearance of dead cells, RTM are now recognized as an integral part of the tissues in which they reside, where they can contribute to a wide range of physiological and pathological processes ${ }^{1-3}$.

RTM populations are very heterogeneous, phenotypically and functionally ${ }^{1-3}$, and the tissue of residence is thought to be a major driver of such diversity ${ }^{4,5}$. According to the niche model, RTM are imprinted by niche-derived tissue-instructive signals that trigger expression of specific differentiation programs, thus tailoring a particular identity, i.e., a phenotypic and functional specialization that fulfills the functional needs of a given tissue ${ }^{5}$. Supporting this, recent mouse studies have shown that distinct precursors have the potential to give rise to the same particular RTM population when the niche is empty ${ }^{5-8}$.

In mice, the well-known alveolar macrophages (AM) differentiate from fetal monocytes, are maintained by self-renewal and are specialized in removal and recycling of surfactant molecules ${ }^{9-11}$. Besides AM, non-alveolar lung macrophages, i.e., the interstitial macrophages (IM), have been shown to contribute to lung immune homeostasis by spontaneously producing the immunosuppressive cytokine IL-10 and preventing the development of aberrant type 2 allergic responses against inhaled allergens $^{12-15}$. In addition, they may substantially contribute to the reduced risk of asthma in a microbe-rich environment (i.e., the so-called hygiene hypothesis ${ }^{16,17}$ ). Indeed, we have reported that exposure to bacterial unmethylated CpG-DNA (CpG) expands tolerogenic IM from monocyte precursors, thereby conferring robust protection against allergic asthma ${ }^{18}$. IL-10-producing IM have also been described in humans ${ }^{19}$, and clinical evidence suggests that they may be functionally impaired in asthmatic patients $^{20}$.

Despite their functional relevance, IM were long merely investigated as a bulk population ${ }^{12-14,18}$. In 2017, Gibbings et al. proposed the existence of three phenotypically distinct IM populations in the steady-state lung based on the differential expression of MHC-II and CD11 $c^{21}$. More recently, Chakarov and colleagues identified two conserved monocyte-derived IM subpopulations across tissues, in mice and humans ${ }^{22}$. In the mouse lung, they characterized nerve-associated Lyve- $1^{\text {lo }} \mathrm{MHC}-\mathrm{II}^{\text {hi }}$ and blood vesselassociated Lyve-1 ${ }^{\text {hi MHC-II }}{ }^{\text {lo }}$ monocyte-derived IM subsets, supporting that the lung IM pool is heterogeneous and encompasses distinct populations carrying their own identity.

Here, we analyze $>3000$ lung tissue mononuclear cells expressing the high affinity immunoglobulin gamma Fc receptor (Fcgr1, CD64) by droplet-based single-cell RNA-sequencing (scRNA-seq) in adult mice. Our study independently confirms the existence of two main subpopulations of lung $\mathrm{IM}^{22}$ and further expands our knowledge about their origin, half-life, localization, functional properties and dynamics upon local exposure to microbial products. Moreover, we uncover a discrete population of extravascular NR4A1-dependent monocytes transitioning from intravascular Ly- $6 \mathrm{C}^{\text {lo }}$ patrolling monocytes towards a specific subset of IM. These results contribute to a better appreciation of the diversity of the lung mononuclear phagocyte system (MPS), an important step toward greater precision and effectiveness of macrophage-targeted therapies.

\section{Results}

Two subsets of IM and monocytes populate the mouse lung. To map mouse lung tissue macrophages (i.e., lung IM) in naive C57BL/6 female wild-type (WT) mice, we performed scRNA-seq using the $10 \mathrm{x}$ Genomics platform ${ }^{23}$. Lung IM were defined as singlet mononuclear cell-enriched $\mathrm{CD}_{4}{ }^{+}$non-autofluorescent
$\mathrm{SSC}^{\mathrm{lo}} \mathrm{F} 4 / 80^{+} \mathrm{CD} 11 \mathrm{c}^{-} \mathrm{Ly}^{-6 \mathrm{C}^{\mathrm{lo}} \mathrm{CD} 64^{+}}$cells $^{18}$ (Fig. 1a, and Supplementary Table 1). Exclusion of lung-resident $\mathrm{F} 4 / 80^{+}$Siglec- $\mathrm{F}^{+}$ eosinophils $^{24}$ based on high SSC was efficient and resulted in minimal loss of IM (Supplementary Fig. 1). In a first experiment, 10 -week-old mice were used and a total of $1715 \mathrm{IM}$, together with 199 AM, were analyzed (Fig. 1b, and Supplementary Fig. 2). In addition, a second scRNA-seq experiment was performed through an independent platform using older mice (i.e., 6-monthold) coming from a different animal facility, and 1682 IM were analyzed (Fig. 1b, and Supplementary Fig. 2).

Non-linear dimensional reduction ( $t$-distributed stochastic neighbor embedding $[t-\mathrm{SNE}]$ ) and graph-based clustering of single cells merged from both experiments identified 4 transcriptionally distinct clusters of monocytes/macrophages (Fig. 1c, and Supplementary Fig. 3a, b) ${ }^{25,26}$. Cluster 3 represented AM (Supplementary Fig. 3c, d) ${ }^{11}$, and Clusters 1, 2, and 4 were distributed in the same proportions in both experiments and were characterized by higher expression of Cx3cr1, Mafb, Cd14, and Cd74 as compared to AM (Supplementary Fig. 3c, d), supporting the contention that it comprised lung tissue IM.

Clusters 1, 2, and 4 exhibited unique transcriptional signatures (Supplementary Fig. 4a, b), including upregulation of transcripts encoding proteins detectable by flow cytometry: MHC-II-related transcripts (e.g., $H 2-E b 1, H 2-A b 1, C d 74$ ) in Cluster 1; transcripts encoding macrophage mannose receptor (Mrc1, encoding CD206), the scavenger receptor Cd163, folate receptor beta precursor (Folr2) and lymphatic endothelium hyaluronan receptor-1 (Lyve1) in Cluster 2; and transcripts encoding angiotensin-converting enzyme (Ace) and low affinity immunoglobulin gamma Fc region receptor IV (Fcgr4, encoding CD16.2) in Cluster 4 (Fig. 1d, and Supplementary Fig. 4c).

Using antibodies directed against CD206 and CD16.2, we showed that expression of these markers was mutually exclusive within $\mathrm{CD}^{+} 4^{+} \mathrm{IM}$ and 3 subpopulations were identified: a minor population of $\mathrm{CD} 16.2^{+} \mathrm{CD} 206^{-}$cells, which co-expressed ACE and corresponded to Cluster 4 (dark blue cells, defined as $\left[\mathrm{CD}^{+} 4^{+}\right]$ CD16.2 ${ }^{+}$[monocytes] hereafter, Fig. 1e-h); CD16.2-CD206 ${ }^{+}$ cells, in which a fraction uniquely expressed Lyve-1 and FOLR2, and corresponding to Cluster 2 (orange cells, defined as CD206 [IM] hereafter, Fig. 1e-h); and CD16.2-CD206- cells, which were expressing significantly higher levels of MHC-II as compared to the other subsets and corresponded to Cluster 1 (light blue cells, defined as $\mathrm{CD}^{206^{-}}$[IM] hereafter, Fig. 1e-j). Of note, $\mathrm{CD}^{206^{-}}$and $\mathrm{CD}^{206^{+}}$subsets largely overlapped with Lyve$1^{\text {lo MHC-II hi }}$ and Lyve-1 ${ }^{\text {hi MHC-II }}{ }^{\text {Mo }}$ IM subsets described by Chakarov et al. ${ }^{22}$, as well as with IM3 and IM1/IM2 subsets described by Gibbings et al., respectively (Supplementary Fig. 5).

Morphologically, CD206 ${ }^{+}$IM uniquely displayed vacuoles in their cytoplasm and a larger size as compared to $\mathrm{CD}_{206}^{-} \mathrm{IM}$ and $\mathrm{CD}^{+}{ }^{+} \mathrm{CD} 16.2^{+}$cells (Fig. 2a, b). Immunostaining against Lamp-1, a lysosomal marker, suggested that the vacuoles seen in $\mathrm{CD}^{206^{+}}{ }^{\mathrm{IM}}$ were lysosomes (Fig. 2c, and Supplementary Fig. 6). Phenotypically, CD206- IM expressed higher levels of CX3CR1, whereas $\mathrm{CD}_{206}{ }^{+} \mathrm{IM}$ expressed higher levels of the macrophageassociated markers MerTK and CD68 as compared to the 2 other subpopulations (Fig. 2c, and Supplementary Fig. 6). Moreover, $\mathrm{CD}^{+} 4^{+} \mathrm{CD} 16.2^{+}$cells expressed higher levels of $\mathrm{CD} 11 \mathrm{~b}$ and CD115 and lower levels of MerTK as compared to both IM subsets (Fig. 2c, and Supplementary Fig. 6), consistent with the idea that $\mathrm{CD} 64^{+} \mathrm{CD} 16.2^{+}$cells were monocytes.

Next, we injected fluorescent-conjugated anti-CD45 antibodies intravenously (i.v.) to label intravascular leukocytes before the sacrifice (Fig. 2d). AM, CD206 ${ }^{+}$, and CD206 ${ }^{-}$IM were only marginally stained by such antibodies (Fig. 2e, f), confirming that these cells were mainly extravascular. Expectedly, nearly all patrolling Ly- $6 \mathrm{C}^{\text {lo }}$ monocytes and a majority of classical Ly- $6 \mathrm{C}^{\text {hi }}$ 
a

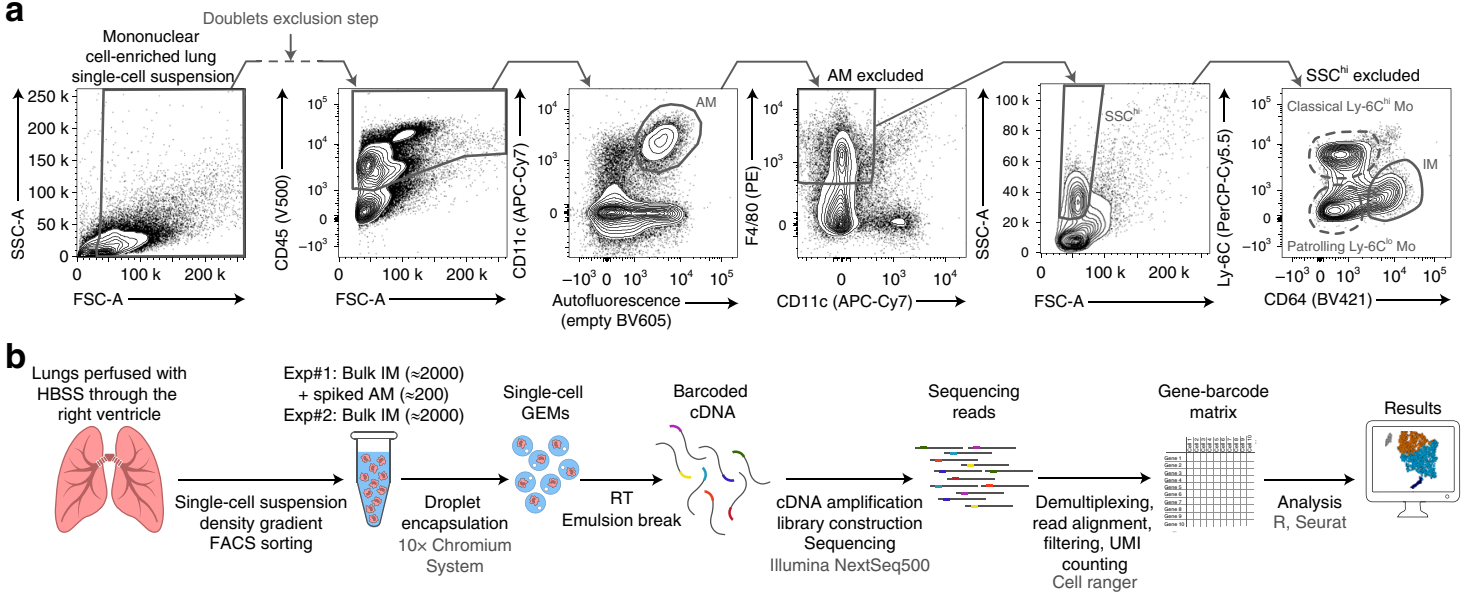

C
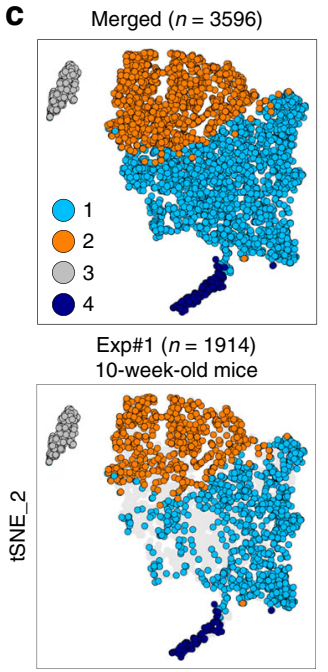

Exp\#2 $(n=1682)$

6-month-old mice

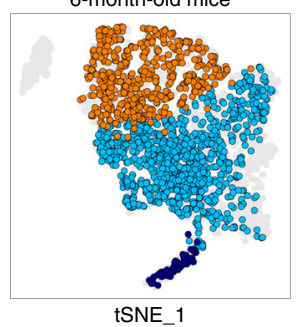

h

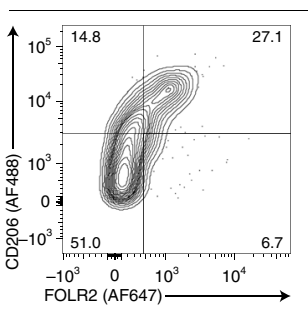

d

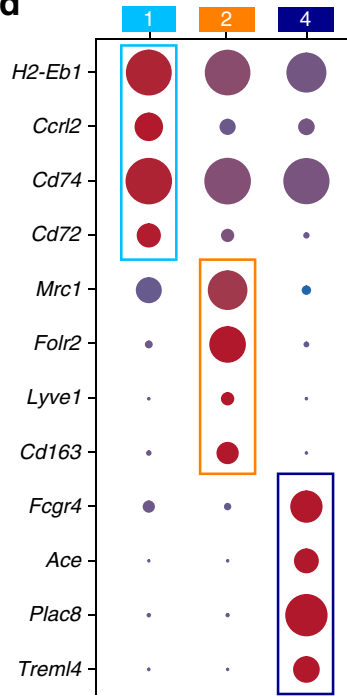

Average expression \%age of cells

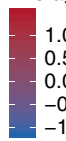

e
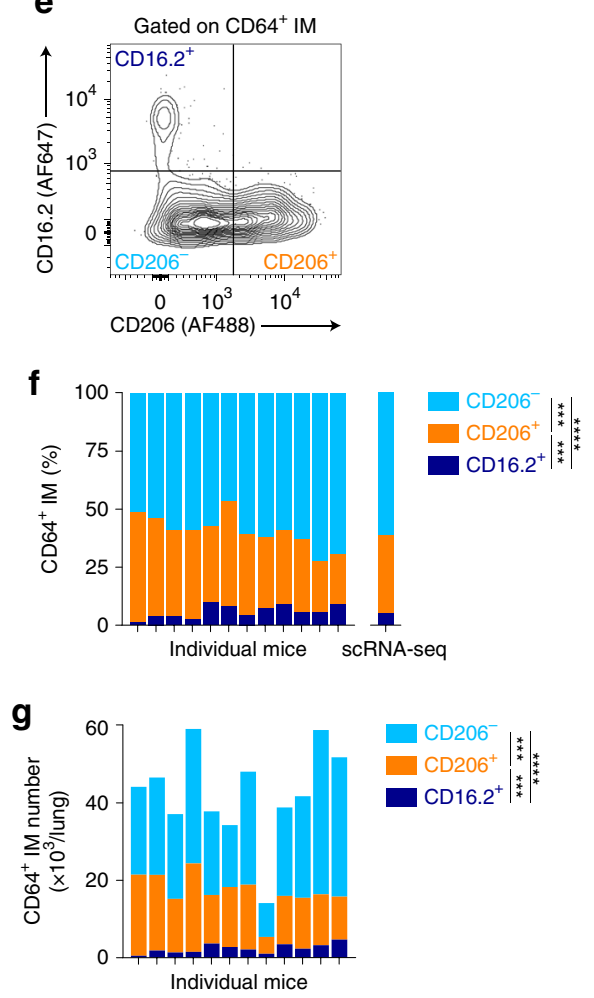

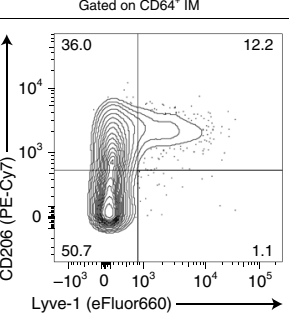

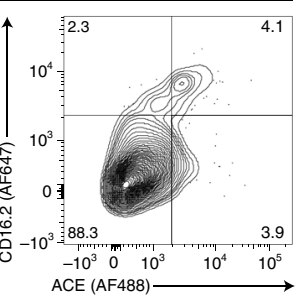

i

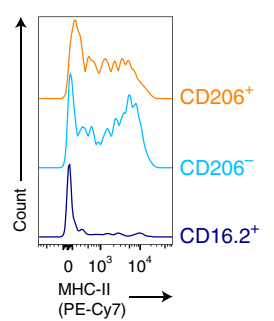

j

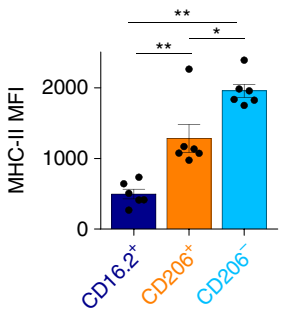

monocytes were labeled, confirming the existence of tissueassociated Ly-6Chi monocytes (Fig. 2e, f) ${ }^{18,27}$. However, the percentage of $\mathrm{CD}^{+} 4^{+} \mathrm{CD} 16.2^{+}$monocytes that were stained with the anti-CD45 in vivo exhibited a high variability and was significantly lower than the one of patrolling Ly-6Clo monocytes (Fig. 2e, f), suggesting that a substantial fraction of $\mathrm{CD}^{+}{ }^{+} \mathrm{CD} 16.2^{+}$monocytes was truly located in the lung tissue.
We also sought to test the ability of each subpopulation to engulf large particles (i.e., E. coli bioparticles conjugated with a $\mathrm{pH}$-sensitive dye), i.e. a functional hallmark of macrophages (Fig. 2g). Like AM, CD64 ${ }^{+} \mathrm{CD} 16.2^{+}$monocytes, CD206 ${ }^{+}$and $\mathrm{CD}^{-}{ }^{-}$IM were able to phagocyte airborne and blood-borne particles, with significantly higher percentages of cells when particles were injected i.t. as compared to i.v. (Fig. 2h). After i.t. 
Fig. 1 ScRNA-seq analysis of CD64+ mononuclear cells in lungs of naive C57BL/6 WT mice. a Gating strategy used for FACS sorting prior to scRNA-seq experiments. $\mathbf{b}$ Experimental pipeline of scRNA-seq experiments. $\mathbf{c} t$-SNE plots depicting the CD64-expressing cells analyzed by scRNA-seq. $n$ indicates the number of cells analyzed after quality control and filtering. $\mathbf{d}$ Dot plots showing average expression of the indicated genes and percentages of cells expressing the genes within each cluster. Examples of transcripts significantly differentially regulated $\left(P_{\text {adj }}<10^{-2}\right)$ between $\mathrm{Cluster} 4,2$ or 1 vs. the 2 other clusters are depicted. e Representative contour plot of CD16.2 and CD206 expression within CD64+ IM, whose quantification is shown in (f). $\mathbf{f}$ Percentage of each mononuclear phagocyte subset among CD64+ bulk IM, assessed by flow cytometry. Stacked bars represent individual mice, and the \% of cells per cluster as identified by scRNA-seq (right bar). g Numbers of each mononuclear phagocyte subset within the steady-state lung. Stacked bars represent individual mice. $\mathbf{h}$ Representative contour plot of the indicated markers within CD64+ IM. Numbers indicate the percentage of cells within the respective gates. The plots are representative of one of 6 individual mice analyzed, each of them giving similar results. i Representative histograms of surface MHC-II expression within each mononuclear phagocyte subset, whose quantification is shown in (j). $\mathbf{j}$ Quantification of MHC-II MFI. $\mathbf{f}, \mathbf{g}$ Data show individual mice and are pooled from 3 independent experiments $(n=12)$. $\mathbf{j}$ Data show mean \pm s.e.m. and are pooled from 2 independent experiments, each symbol representing individual mice $(n=6)$. $P$ values were calculated using non-parametric $\mathbf{f}, \mathbf{g}$ Friedman or $\mathbf{j}$ Mann-Whitney tests for pairwise comparisons. ${ }^{\star} P<$ $0.05 ;{ }^{\star \star} P<10^{-2} ;{ }^{\star \star \star} P<10^{-3} ;{ }^{\star \star \star \star} P<10^{-4}$. Source data are provided as a Source Data file. AM, alveolar macrophage; Exp, experiment; GEM, gel bead in emulsion; IM, interstitial macrophage (sorted in bulk, as shown in a); MFI, Mean Fluorescence Intensity; Mo, monocyte; RT, reverse transcription

injection, percentages of fluorescent $\mathrm{CD}^{2} 06^{+} \mathrm{IM}$ were significantly higher than those of $\mathrm{CD}^{2} 06^{-} \mathrm{IM}$, which might indicate a preferential localization around the airways (Fig. $2 \mathrm{~h}$ ).

So far, our data suggest that, in addition to dendritic cells (DCs) and tissue Ly-6C hi $^{\text {classical monocytes }}{ }^{18,27}$, the lung MPS comprises 3 subpopulations of $\mathrm{Ly}-6 \mathrm{C}^{\mathrm{lo}} \mathrm{CD} 64^{+}$mononuclear phagocytes, namely $\mathrm{CD}^{206^{+}} \mathrm{IM}, \mathrm{CD}^{-06^{-}} \mathrm{IM}$, and nonclassical CD $64^{+} \mathrm{CD} 16.2^{+}$monocytes.

IM subsets are long-lived, unlike NR4A1-dependent monocytes. While previous studies have provided evidence that IM were monocyte-derived cells in adults ${ }^{18,21,22,28}$, they did not exclude the possibility that part of the IM compartment may be selfmaintaining in the tissue. To assess the half-life of IM subpopulations, we used the tamoxifen(TAM)-inducible CX3cr $1^{\text {CreERT2 }}$.Rosa26-LSL-YFP fate-mapping mouse model ${ }^{29}$, and TAM-injected $C \times 3 c r 1^{\text {CreERT2 }}$.Rosa26-LSL-YFP mice were longitudinally evaluated for yellow fluorescent protein (YFP) labeling in lung mononuclear phagocytes (Fig. 3a). Two weeks after injection, $\mathrm{YFP}^{+}$cells were uniquely found among $\mathrm{CD}_{4}{ }^{+}$ subpopulations and Ly-6Clo patrolling monocytes, while YFP was virtually absent in lung Ly-6Chi classical monocytes or DCs (Fig. 3b, c, and Supplementary Fig. 7). Of note, the majority of $\mathrm{CD}^{206^{+}}$and $\mathrm{CD}^{-06^{-}} \mathrm{IM}$ subpopulations were $\mathrm{YFP}^{+}$, whereas less than $20 \%$ of the $\mathrm{CD}^{+} 4^{+} \mathrm{CD} 16.2^{+}$subset was $\mathrm{YFP}^{+}$, similarly to what was observed in Ly-6Clo patrolling monocytes (Fig. 3b, c). In addition, $\mathrm{CD}^{+} 4^{+} \mathrm{CD} 16.2^{+}$cells were all replaced by $\mathrm{YFP}^{-}$ monocytes at week 9 (Fig. 3b, c). Nine and 28 weeks after TAM treatment, the percentages of $\mathrm{YFP}^{+} \mathrm{CD}_{206}{ }^{+}$and $\mathrm{YFP}^{+} \mathrm{CD} 206^{-}$ IM remained high and were not significantly different from those observed 2 weeks post-injection (Fig. 3b, c), supporting that both IM subsets could self-maintain in adults. However, percentages of $\mathrm{YFP}^{+} \mathrm{CD}_{206}^{+}$and $\mathrm{YFP}^{+} \mathrm{CD} 206^{-}$cells were significantly decreased at week 52 as compared to week 2, confirming that both subpopulations were slowly replaced by $\mathrm{YFP}^{-}$monocytes over time (Fig. 3b, c). Interestingly, more than half of the $\mathrm{YFP}^{+}$labeling present at week 2 was still detected 50 weeks later in CD206 ${ }^{+} \mathrm{IM}$, as opposed to less than $24 \%$ in CD206- IM (Fig. 3b, c). In addition, levels of the proliferation marker $\mathrm{Ki}-67$ were significantly greater in $\mathrm{CD}^{206^{+}} \mathrm{IM}$ as compared to $\mathrm{CD} 206^{-} \mathrm{IM}$ and $\mathrm{AM}$ (Fig. 3d), suggesting that $\mathrm{CD} 206^{+}$IM could proliferate and had an increased self-maintenance potential as compared to $\mathrm{CD}^{206^{-}} \mathrm{IM}$.

We have previously shown that bulk IM numbers were not significantly affected in 6-10-week-old $\mathrm{Ccr} 2^{-/-}$or $\mathrm{Nr} 4 \mathrm{a} 1^{-/-}$ mice ${ }^{18}$, whose numbers of blood Ly-6Chi and Ly-6Clo monocytes are impaired, respectively ${ }^{30,31}$ (Supplementary Fig. 8). While numbers of $\mathrm{CD}_{206^{+}}$and $\mathrm{CD}^{-106^{-}}$IM were similar in WT, $\mathrm{Ccr} 2^{-/-}$and $\mathrm{Nr}_{4} \mathrm{al}^{-/-}$mice (Fig. 3e, f), numbers of $\mathrm{CD}^{+}{ }^{+} \mathrm{CD} 16.2^{+}$monocytes were significantly reduced in
$\mathrm{Nr} 4 a 1^{-/-}$mice as compared to WT mice (Fig. 3e, f), like those of Ly- $6 \mathrm{C}^{\text {lo }}$ monocytes, demonstrating that $\mathrm{CD} 64^{+} \mathrm{CD} 16.2^{+}$ monocytes depended on NR4A1 for their presence in the lung.

The similarities between $\mathrm{CD} 64^{+} \mathrm{CD} 16.2^{+}$monocytes and intravascular Ly-6Clo patrolling monocytes (i.e., half-life, dependence on NR4A1 and surface phenotype [Supplementary Fig. 9a, b]) supported the possibility that $\mathrm{CD} 64^{+} \mathrm{CD} 16.2^{+}$monocytes actually derived from Ly-6C ${ }^{\text {lo }}$ patrolling monocytes, but expressed CD64 and were partly extravascular. If $\mathrm{CD} 64^{+} \mathrm{CD} 16.2^{+}$monocytes enter the tissue, they should be imprinted by tissue-instructive signals and, hence, exhibit a transcriptomic profile that is distinct from the one of intravascular Ly-6Clo monocytes. Hence, we compared CD64- Ly-6C lo patrolling monocytes (Supplementary Fig. 9c-e) with $\mathrm{CD}^{+} 4^{+} \mathrm{CD} 16.2^{+}$monocytes by scRNA-seq and found that they segregated in separated clusters (Supplementary Fig. 9f). Moreover, we found that many of the most upregulated transcripts in $\mathrm{CD}^{+} 4^{+} \mathrm{CD} 16.2^{+}$monocytes (Supplementary Fig. 9g-i) were also found to be significantly upregulated in IM as compared to AM (see Supplementary Fig. 3d). These data support the notion that CD64 ${ }^{+} \mathrm{CD} 16.2^{+}$monocytes can be distinguished from Ly-6Clo patrolling monocytes by their expression of tissue-specific IMrelated genes, likely as a result of tissue-derived imprinting.

Altogether, our data identified two main subsets of long-lived monocyte-derived IM, with CD206 ${ }^{+}$IM exhibiting a greater halflife than $\mathrm{CD}^{206^{-}} \mathrm{IM}$, as well as short-lived NR4A1-dependent CD64 ${ }^{+} \mathrm{CD} 16.2^{+}$monocytes.

$\mathrm{CD} 206^{+}$and $\mathrm{CD206}^{-} \mathrm{IM}$ preferentially populate distinct niches. To assess the preferential localization of the two IM subpopulations and of $\mathrm{CD} 64^{+} \mathrm{CD} 16.2^{+}$monocytes, we used confocal microscopy. Lung sections of $C x 3 c r 1^{\mathrm{GFP} / \mathrm{GFP}}$ mice were stained with antibodies directed against GFP, CD68 (as a macrophage marker) and either CD206, MHC-II or CD16.2. Of note, we observed only a minor fraction of $\mathrm{CD}^{+} 8^{+}$cells expressing simultaneously CD206 and MHC-II using a combined antiCD206 and anti-MHC-II staining (Supplementary Fig. 10). Hence, $\mathrm{CX} 3 \mathrm{CR} 1^{+} \mathrm{CD}^{+} 8^{+} \mathrm{CD} 206^{+}, \mathrm{CX} 3 \mathrm{CR} 1^{+} \mathrm{CD} 68^{+} \mathrm{MHC}^{-} \mathrm{II}^{+}$ and $\mathrm{CX} 3 \mathrm{CR} 1^{+} \mathrm{CD} 68^{+} \mathrm{CD} 16.2^{+}$triple-positive cells were quantified in multiple sections and fields to evaluate the spatial distribution of $\mathrm{CD}^{206^{+}} \mathrm{IM}, \mathrm{CD}^{206^{-}} \mathrm{IM}$ and $\mathrm{CD} 64^{+} \mathrm{CD} 16.2^{+}$ monocytes, respectively (Fig. $4 \mathrm{a}, \mathrm{b}$ ). On the one hand, we found that $\mathrm{CD}^{206^{+}}$IM were preferentially found in the bronchial interstitium, whereas CD206- ${ }^{-} \mathrm{IM}$ and $\mathrm{CD} 64^{+} \mathrm{CD} 16.2^{+}$monocytes were mainly located in the alveolar interstitium (Fig. 4a, b). On the other hand, since Chakarov et al. reported that peribronchial Lyve- $1^{\text {lo }} \mathrm{MHC}-\mathrm{II}{ }^{\text {hi }}$ and Lyve- $1^{\text {hi }}$ MHC-II ${ }^{\text {lo }}$ IM subsets were mainly associated with nerves and blood vessels, respectively ${ }^{22}$, we used antibodies against CD31 and Tubb3 to stain nerves and endothelial cells. While CD206 ${ }^{+}$IM were associated 
a

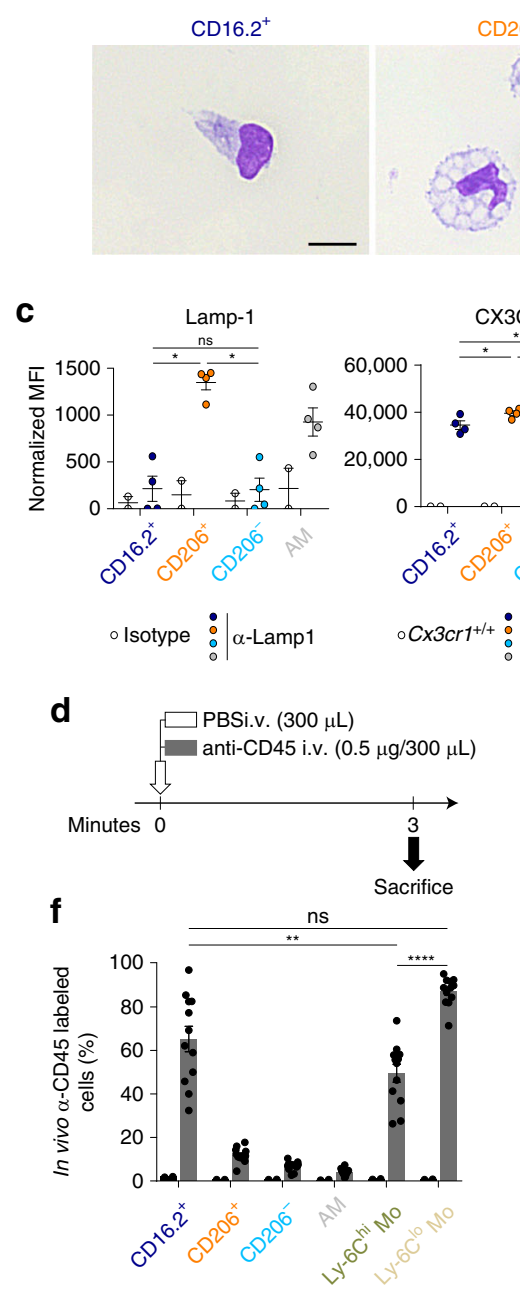

g

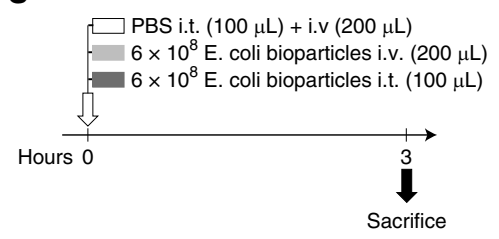

b

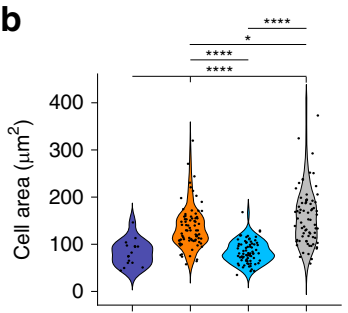

C

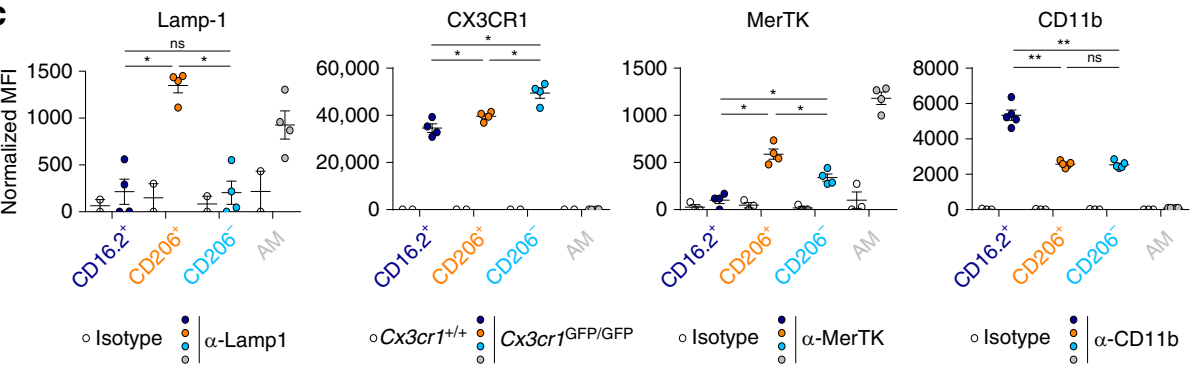

CD206

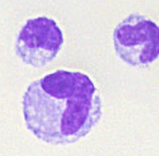

AM

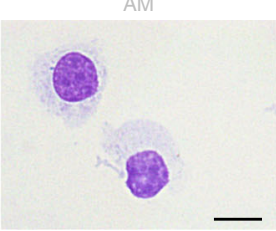

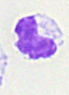

\section{$\mathbf{e}$}

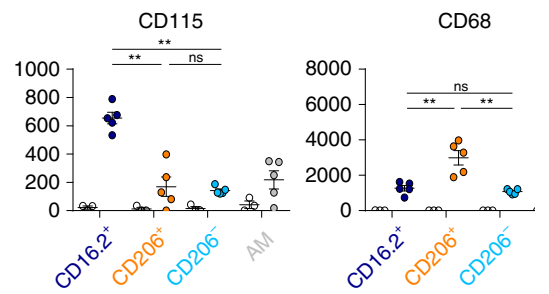

olsotype $: \begin{array}{lll}: & \alpha-C D 115 \\ 0 & & \end{array}$ olsotype $: \begin{array}{ll}: & \alpha-C D\end{array}$

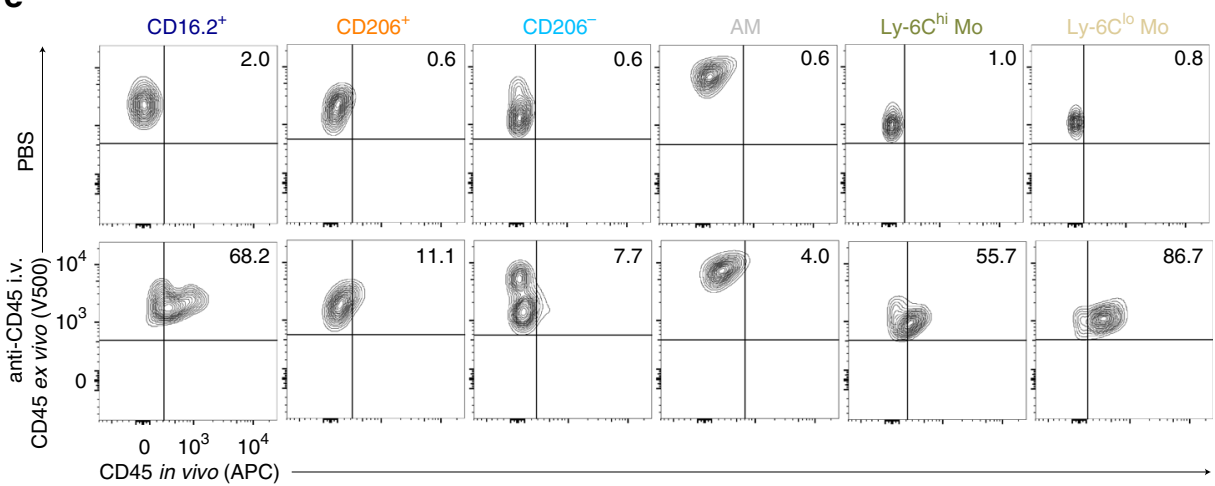

h

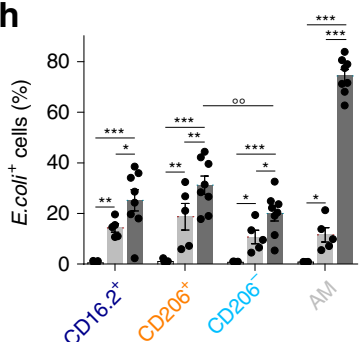

Fig. 2 Morphology, phenotype, tissue association and phagocytic abilities of lung CD64+ subpopulations. a Representative photograph of the indicated FACS-sorted populations. b Quantification of the size of cells presented as violin plots (height: cell area; width abundance of cells) and individual dots representing single cells. c Quantification of expression of the indicated markers as compared to control cells. $\mathbf{d}$ Experimental outline for panels (e, $\mathbf{f}$ ). e Representative contour plots showing binding of anti-CD45 in vivo vs. anti-CD45 ex vivo antibodies on the indicated cell populations. Numbers indicate the percentage of double-positive cells. $\mathbf{f}$ Percentage of cells positive for anti-CD45 in vivo and ex vivo stainings within the indicated populations. $\mathbf{g}$ Experimental outline for panel (h). $\mathbf{h}$ Percentage of $E$. coli bioparticle-positive cells $3 \mathrm{~h}$ after i.v. or i.t. administration. Data show (b) individual cells pooled from 3 independent sorting experiments (CD16.2 ${ }^{+}, \mathrm{CD}_{206^{+}}, \mathrm{CD} 206^{-}, \mathrm{AM}: n=16,77,75,72$, respectively), or (c, $\left.\mathbf{f}, \mathbf{h}\right)$ mean \pm s.e.m., as well as individual mice (c, $n=4-5 ; \mathbf{f}, n=12 ; \mathbf{h}, n=5-8$ /group), and are pooled from 2 independent experiments. $P$-values were calculated using (c, f) non-parametric Mann-Whitney tests for pairwise comparisons or $(\mathbf{h})$ a linear mixed model on $\log (\mathrm{y}+1)$-transformed values with Tukey's post hoc test. ${ }^{\star} P<0.05$; ${ }^{\star \star} /{ }^{\circ 0} P<$ $10^{-2} ;{ }^{\star \star \star} P<10^{-3}{ }^{\star \star \star \star \star} P<10^{-4}$; ns, not significant. Empty circles compare \% of E. colit cells after i.t. injection in CD206 ${ }^{+}$vs. CD206 ${ }^{-}$IM subsets. Source data are provided as a Source Data file. i.t., intratracheal; i.v., intravenous; MFI, Mean Fluorescence Intensity. Scale bar $=10 \mu \mathrm{m}$

with blood vessels (Fig. 4c), the preferential localization of peribronchial CD206- IM next to nerves was, however, less obvious, which is likely due to the close association of blood vessels and nerves in the peribronchial areas of the lung (Fig. 4d).

These data support that the two IM subpopulations are found in distinct micro-anatomical niches, which may dictate specific functional specializations.
$\mathrm{CD206}^{+}$and $\mathrm{CD206}^{-} \mathrm{IM}$ exhibit distinct functional properties. Next, we performed Gene Ontology (GO) enrichment analyses to gain insights into the functional properties of $\mathrm{CD} 64^{+} \mathrm{CD} 16.2^{+}$ monocytes and IM subpopulations. First, comparison between $\mathrm{CD} 64^{+} \mathrm{CD} 16.2^{+}$monocytes and IM subsets revealed an enrichment, in $\mathrm{CD} 64^{+} \mathrm{CD} 16.2^{+}$monocytes, in transcripts involved in leukocyte cell-cell adhesion, integrin-mediated signaling 

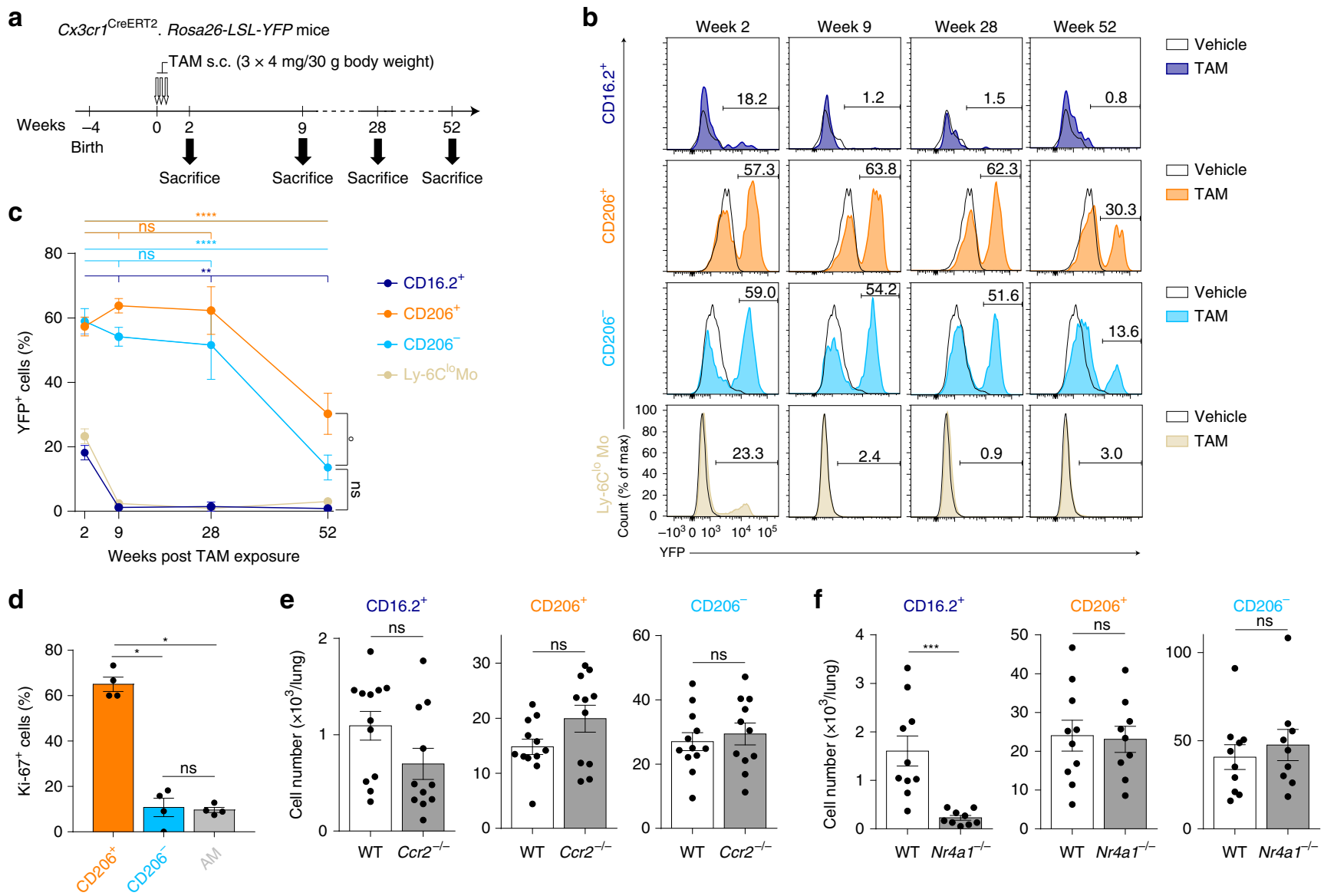

Fig. 3 Maintenance of lung tissue CD64+ mononuclear phagocytes in adult C57BL/6 mice. a Experimental outline for panels (b, c). Briefly, at 4 weeks of age, Cx3cr7 CreERT2 . Rosa26-LSL-YFP mice were treated with TAM s.c. 3 times, 48h apart. Mice were analyzed for YFP expression 2, 9, 28, and 52 weeks later. b Representative histograms of YFP expression within the indicated populations. Numbers indicate the percentage of YFP+ cells, as quantified in (c). c Percentage of YFP ${ }^{+}$cells within the indicated populations, assessed by flow cytometry. $\mathbf{d}$ Percentages of Ki-67+ cells in the indicated populations.

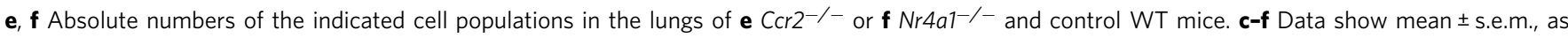
well as individual mice in (d-f) $(\mathbf{c}, n=10 ; \mathbf{d}, n=4 ; \mathbf{e}, \mathbf{f}, n=9-12)$ and are pooled from 2 to 3 independent experiments. $P$-values were calculated using (c) a two-way ANOVA with Tukey's post hoc test, $\mathbf{d}$ non-parametric Mann-Whitney test for pairwise comparisons or $\mathbf{e}$, $\mathbf{f}$ a two-tailed unpaired Student's $t$-test. ${ }^{\star} P<0.05{ }^{\star \star \star} P<10^{-2} ;{ }^{\star \star \star} P<10^{-3} ;{ }^{\star \star \star \star} P<10^{-4} ; \mathrm{ns}$, not significant. In $\mathbf{c}$ the empty circle compares CD206 ${ }^{+}$and CD206 ${ }^{-}$IM at week 52. Source data are provided as a Source Data file. s.c., subcutaneous; TAM, tamoxifen

pathway, positive regulation of cytoskeleton organization and myeloid leukocyte migration (Table 1, Supplementary Fig. 11 and Supplementary Table 2), supporting the possibility that $\mathrm{CD} 64^{+}$ CD16.2 $2^{+}$monocytes may be actively extravasating in the lung tissue. Second, we found that the upregulated transcripts in $\mathrm{CD}^{206^{+}} \mathrm{IM}$ were enriched for processes related to the positive regulation of leukocyte chemotaxis, response to wounding and receptor-mediated endocytosis, consistent with their phenotype and lysosomal vacuoles (Table 1, Supplementary Fig. 11 and Supplementary Table 2). Third, CD206- IM had increased expression of transcripts associated with antigen processing and presentation, regulation of $\mathrm{T}$ cell activation and defense response (Table 1, Supplementary Fig. 11 and Supplementary Table 2).

To complement these mRNA data at the protein level, we performed a proteome profiling on the supernatants of FACSsorted $\mathrm{CD}_{206^{+}}$and $\mathrm{CD} 206^{-}$IM (Fig. 5a, b). CD206 ${ }^{+}$IM were characterized by an elevated chemokine secretory profile (e.g., CXCL11, CXCL10, CXCL9, CXCL2, CCL12), a higher secretion of immunoregulatory cytokines (IL-10, IL1-Ra) and factors regulating cell growth and differentiation, such as leukemia inhibitory factor (LIF), amphiregulin (AREG), or IL-7 (Fig. 5a, b). Conversely, CD206 ${ }^{-}$IM secreted larger amounts of Pentraxin 3
(PTX3), secreted in response to inflammatory signals and facilitating pathogen recognition ${ }^{32}$, the p40 subunit of the type 1 helper T cell (Th1)-differentiating cytokine IL-12, and the B and T lymphocyte chemoattractant CXCL13 and CCL5, respectively (Fig. 5a, b). GO analysis also showed that both IM subsets expressed high levels of genes implicated in the cellular response to LPS as compared to $\mathrm{CD} 64^{+} \mathrm{CD} 16.2^{+}$monocytes (Table 1 , Supplementary Fig. 11 and Supplementary Table 2). Of note, ex vivo LPS stimulation potentiated the secretion of chemokines and immunoregulatory cytokines in $\mathrm{CD} 206^{+} \mathrm{IM}$, and of PTX3, IL12p40 and CCL5 in CD206- IM (Fig. 5a, b).

At steady-state, we and others have shown that, upon engagement of Toll like receptor (TLR)4 (i.e., the main receptor for LPS) and the adaptor molecule MYD88, bulk IM could fulfill important tolerogenic tasks by inhibiting DC functions via IL-10dependent mechanisms, thus preventing the development of asthma in animal models ${ }^{12,18}$. Proteome profiler data supported that CD206 ${ }^{+}$IM were the main IL-10-secreting cells (Fig. 5a, b). To validate these findings, we assessed IL-10 expression in lung monocyte/macrophage populations from IL-10- $\beta$-lactamase reporter ITIB mice $^{33}$ (Fig. 5c, d). First, we observed that AM, Ly-6C ${ }^{\text {hi }}$ classical and Ly-6C ${ }^{\text {lo }}$ patrolling monocytes exhibited low 
a
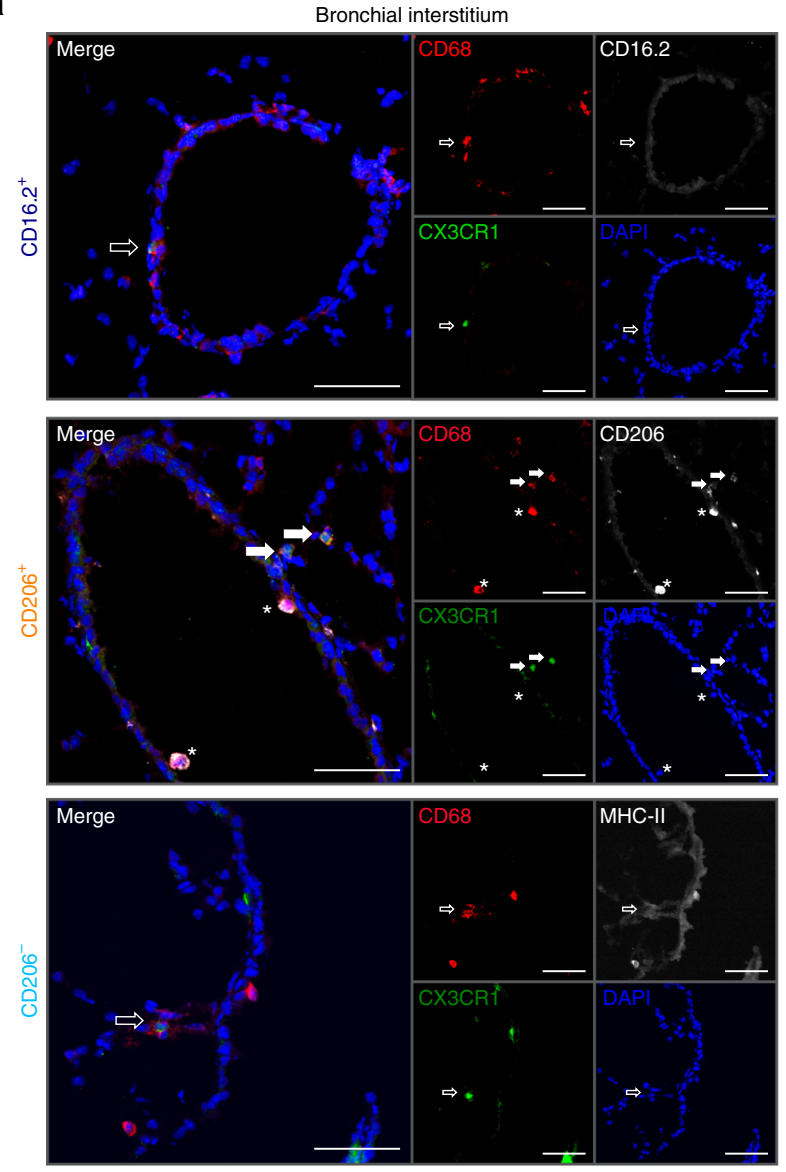

b

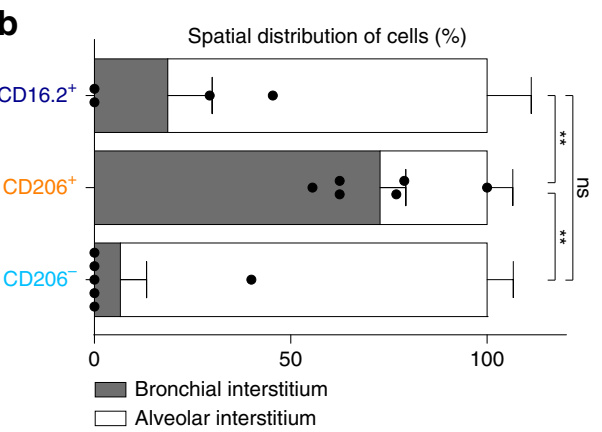

C
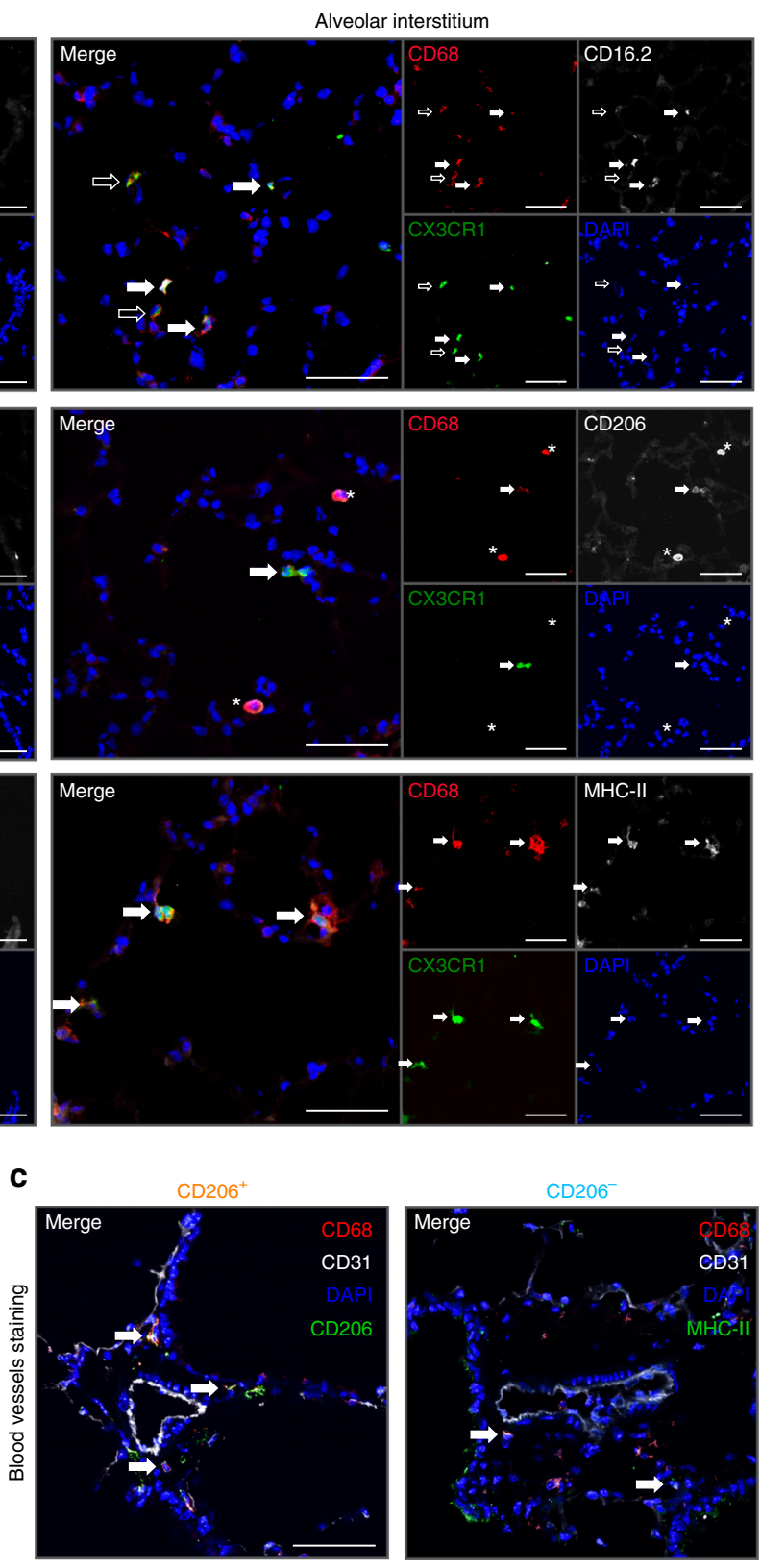

d
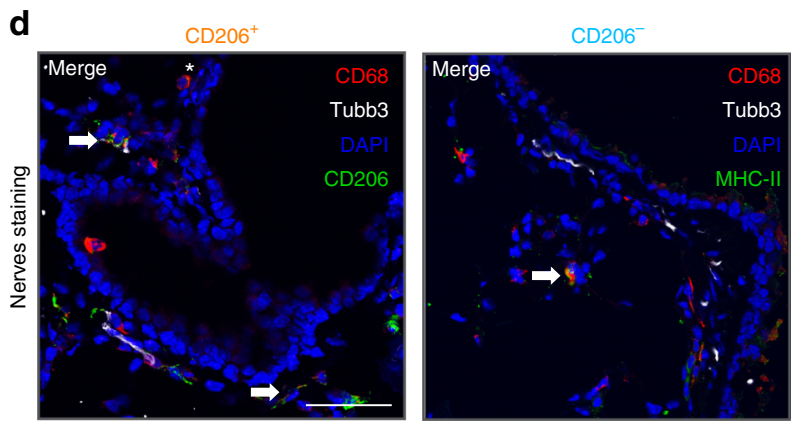

Altogether, our data support that, in addition to their distinct phenotype and localization, IM subpopulations are characterized by unique functional properties. CD206 ${ }^{+}$IM exhibit a prominent tolerogenic and chemokine secretory profile, whereas CD206- IM have a typical antigen-presenting cell profile. Besides IM subsets, a fraction of $\mathrm{CD}^{+} 4^{+} \mathrm{CD} 16.2^{+}$monocytes also express IL-10, a functional hallmark of lung $\operatorname{IM}^{12,15,18,19}$. percentages of IL- $10^{+}$cells (Fig. $5 \mathrm{c}$, d). Second, we found that the percentage of $\mathrm{CD}_{206}{ }^{+}$IM expressing IL-10 was significantly higher than the one of CD206- IM (Fig. 5c, d). Third, we showed that the percentage of $\mathrm{IL} 10^{+} \mathrm{CD} 64^{+} \mathrm{CD} 16.2^{+}$monocytes was significantly higher than the one of $\mathrm{IL}-10^{+}$patrolling $\mathrm{Ly}-6 \mathrm{C}^{\mathrm{lo}}$ monocytes (Fig. $5 \mathrm{c}, \mathrm{d}$ ), pointing out another notable difference between $\mathrm{CD} 64^{+} \mathrm{CD} 16.2^{+}$and patrolling monocytes. 
Fig. 4 Localization of lung CD64+CD16.2+ monocytes, CD206+ IM and CD206- IM a Confocal microscopy pictures of lung sections from Cx3cr7GFP/GFP mice (CX3CR1 [green]; CD68 [red]; DAPI [blue]; CD16.2, MHC-II or CD206 [white]). CD64+CD16.2+ monocytes, CD206 ${ }^{+}$IM and CD206 ${ }^{-}$IM were

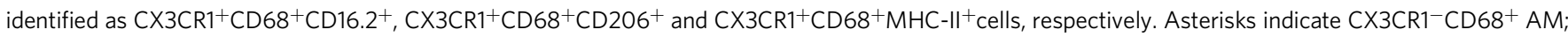
plain or empty arrows indicate CX3CR1 ${ }^{+} \mathrm{CD} 68^{+}$cells expressing or not the marker of interest (i.e., CD16.2, CD206 or MHC-II), respectively. b Preferential distribution of the indicated populations in the peribronchial/perivascular area vs. the alveolar parenchyma. $\mathbf{c}$, $\mathbf{d}$ Lung sections of C57BL/6 WT mice were analyzed: CD68 [red]; c CD31 or d Tubb3 [white]; DAPI [blue]; MHC-II, CD206 or CD16.2 [green]). CD206+ IM, CD206- IM and CD64+CD16.2+ monocytes were identified as $\mathrm{CD} 8^{+} \mathrm{CD}^{206}{ }^{+}, \mathrm{CD} 68^{+} \mathrm{MHC}-\mathrm{II}^{+}$and $\mathrm{CD} 68^{+} \mathrm{CD} 16.2^{+}$cells, respectively. $\mathbf{b}$ Data show mean \pm s.e.m. and are pooled from 2 independent batches of mice $(n=4-6)$. P-values were calculated using a Kruskal-Wallis test, and pairwise comparisons were estimated using Mann-Whitney tests. ${ }^{\star \star} P<10^{-2}$; ns, not significant. Source data are provided as a Source Data file. Scale bars $=(\mathbf{a}) 100 \mu \mathrm{m} ;(\mathbf{c}, \mathbf{d}) 50 \mu \mathrm{m}$

Table 1 Gene Ontology analysis of the transcriptomic profiles of IM subpopulations

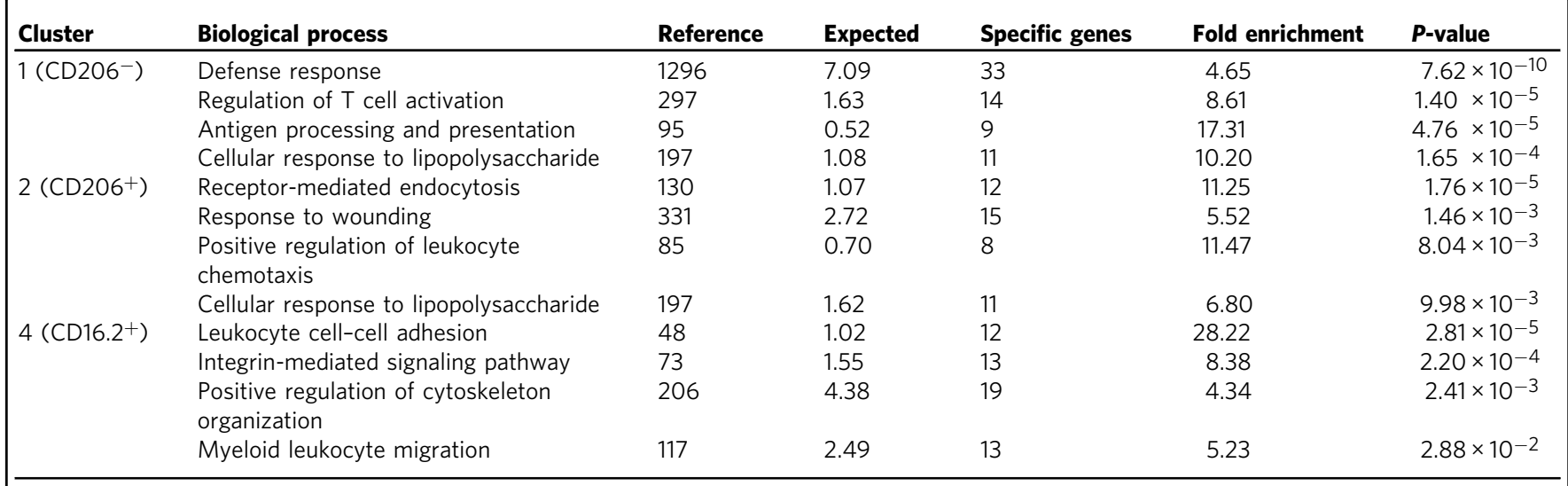

Reference indicates the number of genes in the gene set, Expected the average number of genes expected to be present if there is no enrichment, and Specifc genes the number of genes from the gene set that are upregulated in the indicated Cluster. P-values were calculated using a two-tailed Mann-Whitney $U$ test with Benjamini-Hochberg False Discovery Rate correction

Exposure to TLR ligands differentially modulates IM subsets. We reported previously that local instillation of TLR ligands, such as Pam3CSK4, LPS, and CpG (i.e., TLR1/2, TLR4, and TLR9 ligands, respectively) promoted an expansion of bulk $\mathrm{IM}^{18}$. Here, we exposed mice to Pam3CSK4, LPS, and CpG and performed time-course analysis of IM subsets (Fig. 5e). Pam3CSK4 and LPS induced similar dynamic changes, characterized by transient increases in numbers of $\mathrm{CD} 64^{+} \mathrm{CD} 16.2^{+}$cells followed by a subsequent expansion of CD206- IM (Fig. 5f, g). LPS also significantly increased numbers of $\mathrm{CD} 206^{+} \mathrm{IM}$ at day 3 as compared to baseline (Fig. 5f). After CpG treatment, the profile was drastically different as compared to LPS or Pam3CSK4, with a more robust and sustained increase in numbers of $\mathrm{CD} 64^{+} \mathrm{CD} 16.2^{+}$ cells, reaching a peak at day 7 , and a gradual increase in numbers of CD206- IM peaking at day 14 (Fig. 5f, g). Of note, increases in numbers of CD206 ${ }^{-}$cells were associated with a drop in global MHC-II expression by those cells (days 3-7, Fig. 5h). Conversely, MHC-II expression of $\mathrm{CD} 64^{+} \mathrm{CD} 16.2^{+}$cells gradually increased from day 5 to day 14, regardless of the treatment (Fig. 5h). Twenty-eight days after treatment, MHC-II expression was equal or even higher than day 0 in each subset, regardless of the treatment (Fig. 5h). Functionally, CpG was by far the most potent stimulus in triggering IL-10+ $\mathrm{IM}$, which was restricted to the CD $64^{+}$CD $16.2^{+}$compartment (Fig. 5i).

RNA velocity identifies local precursors of $\mathrm{CD}^{206}{ }^{-} \mathrm{IM}$. To gain insights into cell fate decisions, we applied RNA velocity analysis ${ }^{34}$ to our scRNA-seq datasets, i.e. IM subsets, AM, CD64 ${ }^{+} \mathrm{CD} 16.2^{+}$ monocytes, Ly-6C ${ }^{\text {lo }}$ patrolling and Ly-6Chi classical monocytes (Supplementary Fig. 12). RNA velocity utilizes the balance between unspliced and spliced mRNAs to estimate the transition probability of individual cells ${ }^{34}$. Velocities, substantiated by arrows, can easily be projected on the $t$-SNE plot representing the merged scRNA-seq datasets on the basis of the similarity between the extrapolated state of a single cell and the static state of other cells in the local neighborhood (Fig. 6a, b, and Supplementary Fig. 13). Confirming the idea that both IM subsets arise from independent lineages ${ }^{22}$, RNA velocities of CD206 ${ }^{-}$and CD206 ${ }^{+}$ IM suggested that both IM subpopulations were relatively stable and independent from each other, as no clear transition could be observed from one subpopulation to the other (Fig. 6b, and Supplementary Fig. 14).

Interestingly, RNA velocities of $\mathrm{CD} 64^{+} \mathrm{CD} 16.2^{+}$monocytes were significantly higher than those of $\mathrm{Ly}-6 \mathrm{C}^{\text {lo }}$ patrolling monocytes or CD206- IM, supporting their dynamic transition state, and were pointing towards $\mathrm{CD}^{206^{-}} \mathrm{IM}$ (Fig. 6b, c). Moreover, transition probability analysis of Ly- $6 \mathrm{C}^{\text {lo }}$ patrolling and CD64 ${ }^{+} \mathrm{CD} 16.2^{+}$monocytes suggested that they could give rise to $\mathrm{CD}^{+}{ }^{+} \mathrm{CD} 16.2^{+}$monocytes and $\mathrm{CD} 206^{-} \mathrm{IM}$, respectively (Fig. 6d), supporting that $\mathrm{CD}^{+} 4^{+} \mathrm{CD} 16.2^{+}$monocytes are mobilizable, on a timescale of hours ${ }^{34}$, to become CD206- IM. Using Slingshot package for pseudo-time inference analysis ${ }^{35}$, we found a continuum from Ly-6Clo monocytes towards CD206 ${ }^{-}$ $\mathrm{IM}$, with $\mathrm{CD}^{+} 4^{+} \mathrm{CD} 16.2^{+}$monocytes as an intermediate state (Fig. 6e). Among the gene expression changes driving such transition, we observed a downregulation of a patrolling monocyte signature (e.g., $C e b p b$, encoding $\mathrm{C} / \mathrm{EBP} \beta$, essential for Ly-6 $\mathrm{C}^{\text {lo }}$ monocyte survival ${ }^{36}$, Plac8, Treml4, Ace [see Supplementary Fig. 9g, h]) concomitantly to an upregulation of many previously identified IM-related transcripts, including MHC-II-related transcripts (see Supplementary Figs. 3d and 9h, i) (Fig. 6f).

NR4A1-dependent monocytes can differentiate into $\mathrm{CD}^{206}{ }^{-} \mathrm{IM}$. Finally, we sought to validate our computational-based conclusions in vivo. First, we generated bone marrow (BM) competitive CD45.1/2 chimeras engrafted with CD45.1 ${ }^{+}$WT and CD45.2 $2^{+}$ 

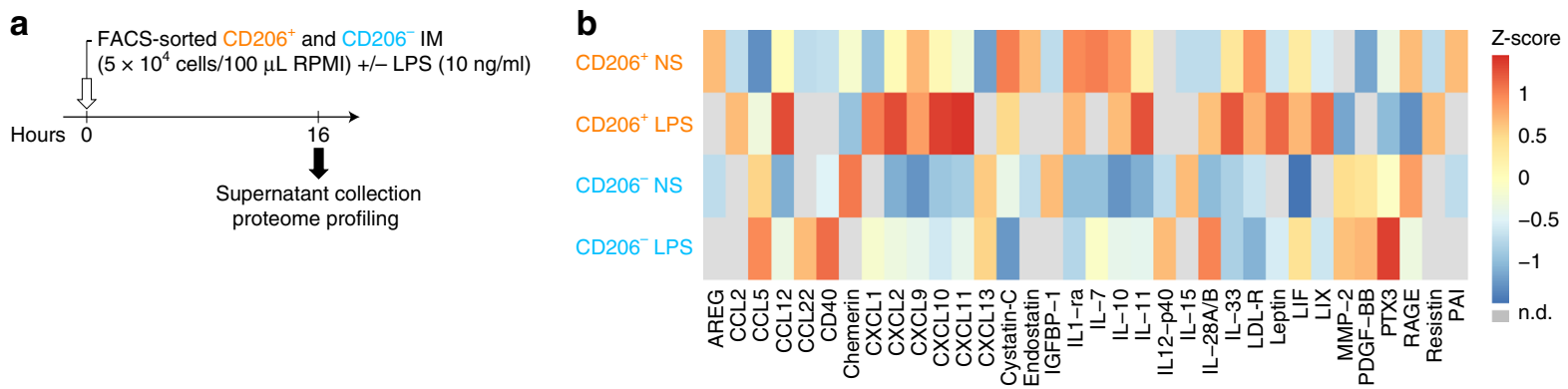

C CCF4-loaded cells from IL-10 reporter ITIB or WT mice

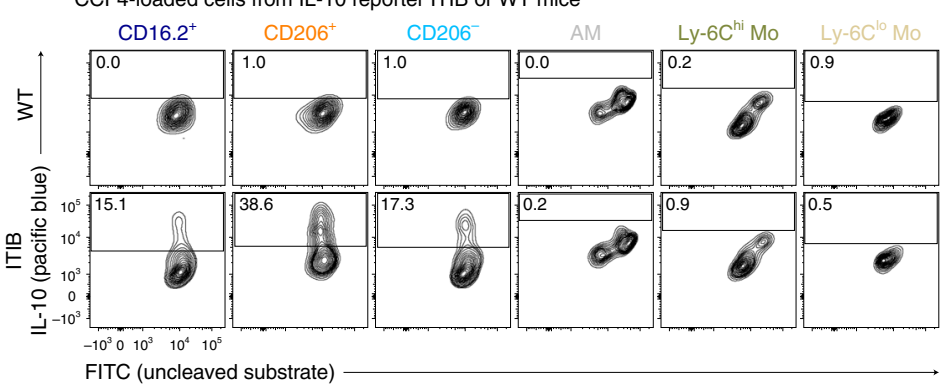

d
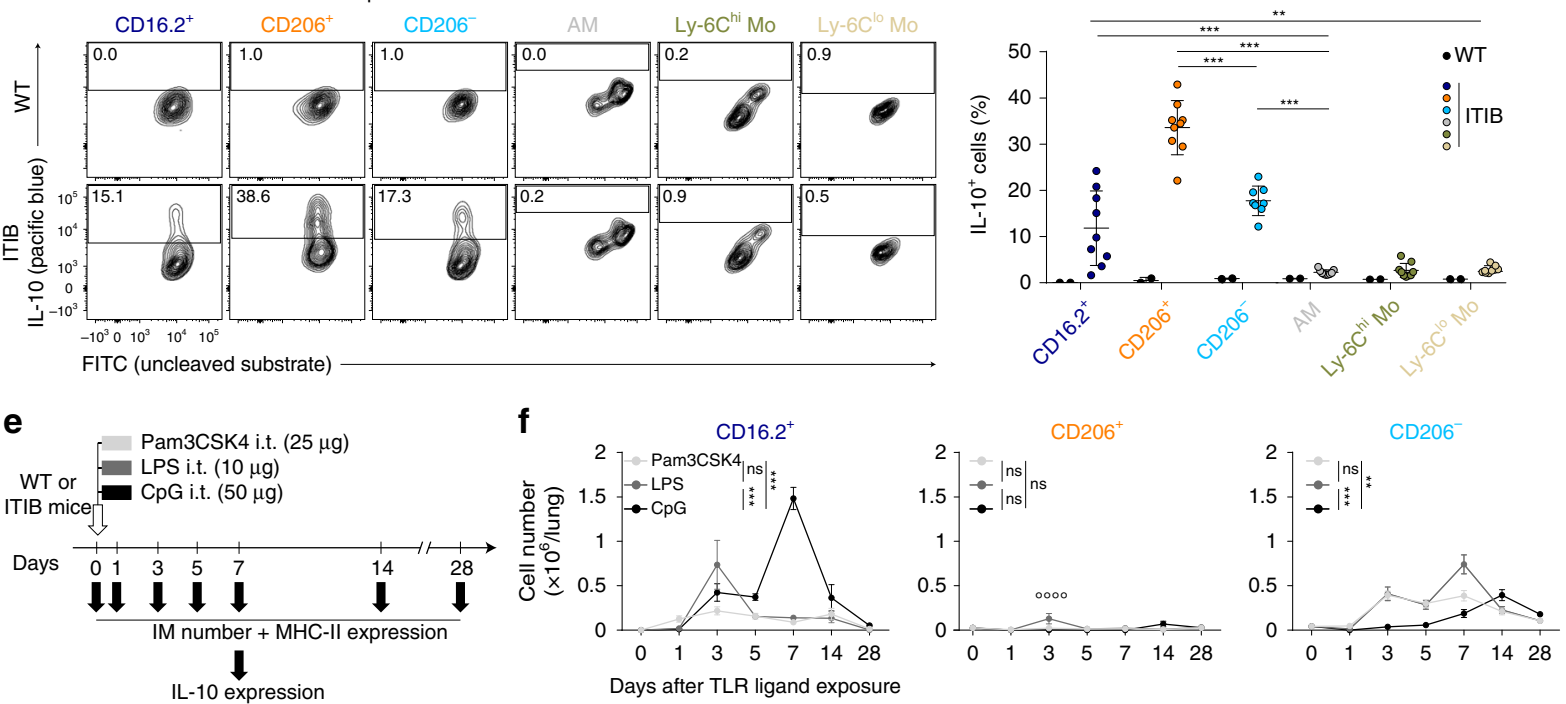

g
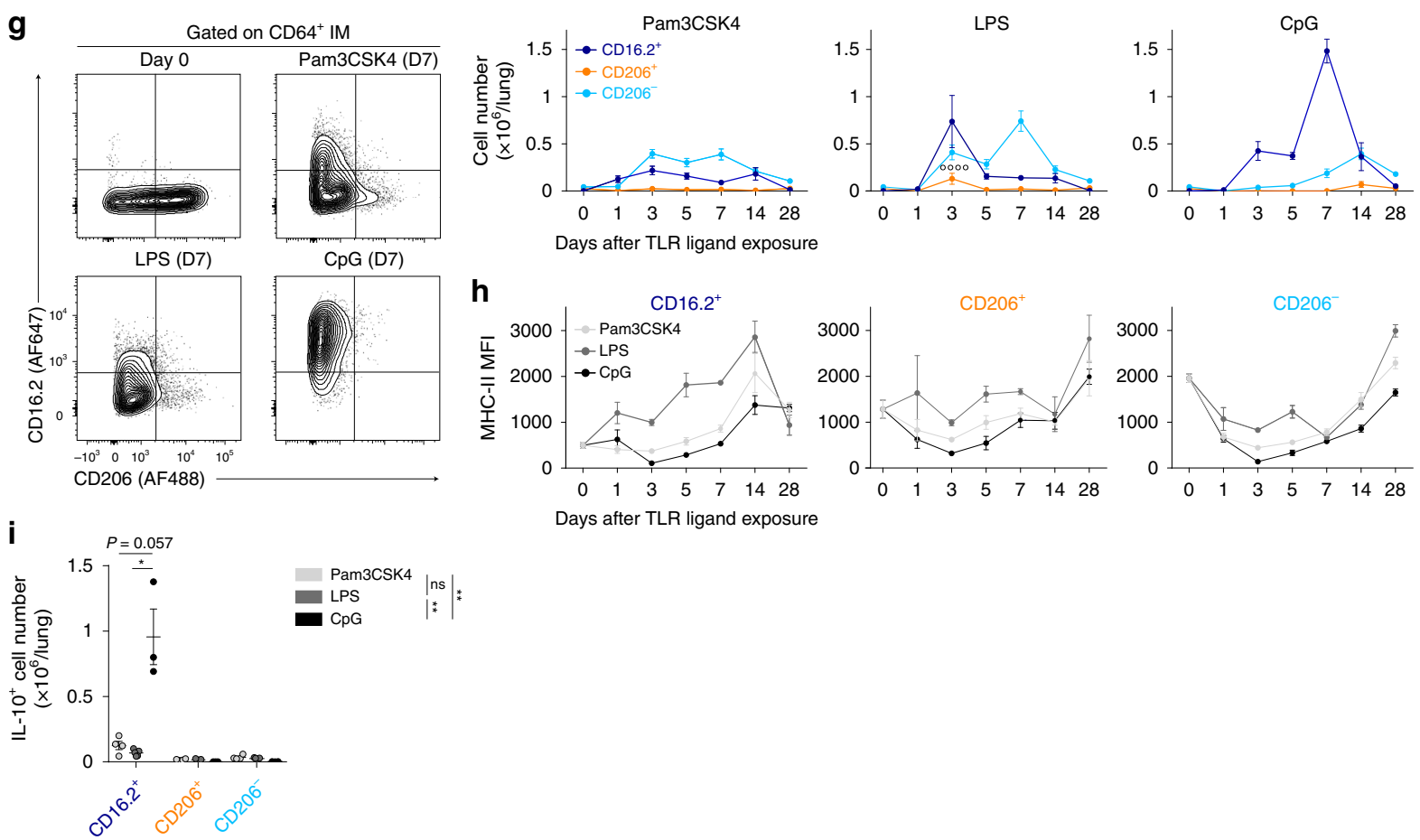

$N r 4 a 1^{-1-}$ BM cells (Fig. 7a). Six weeks after reconstitution, $>85 \%$ of blood Ly-6Clo patrolling monocytes were of CD45.1 $1^{+}$WT origin, whereas less than $25 \%$ of NR4A1-independent B lymphocytes and neutrophils were of CD45.1 ${ }^{+}$WT origin (Fig. 7b). After 14 weeks, repopulated lung AM and both IM subsets displayed a chimerism similar to NR4A1-independent cells, confirming that such niches were repopulated by CCR2-dependent classical monocytes after lethal irradiation (Fig. $7 \mathrm{~b})^{18}$. Nevertheless, there was a significant enrichment, in repopulated $\mathrm{CD} 64^{+} \mathrm{CD} 16.2^{+}$monocytes, in cells of CD $45.1^{+}$WT origin as compared to NR4A1-independent cells (Fig. 7b), supporting the idea that even in such extreme conditions, Ly-6C ${ }^{\text {lo }}$ patrolling monocytes substantially contributed to the pool 
Fig. 5 Functional properties of IM subpopulations at steady-state and dynamic regulation after airway exposure to microbial products. a Experimental outline for (b). FACS-sorted IM subpopulations were cultured ex vivo overnight with or without LPS, and supernatants were subjected to proteome profiling. $\mathbf{b}$ Heatmap depicting the relative abundance of the indicated molecules in the supernatants of non-stimulated (NS) or LPS-stimulated (LPS) lung IM subpopulations. Data represent the mean and are representative of one of 2 independent sorting experiments. c Representative contour plots showing steady-state IL-10 expression as assessed by detection of $450 \mathrm{~nm}$ fluorescence (blue fluorescent product of the cleaved CCF4 substrate) in CCF4-loaded cells isolated from IL-10- $\beta$-lactamase reporter ITIB or WT control mice. Numbers indicate $\%$ of IL-10+ cells within the cell populations, as quantified in (d). d Percentages of $\mathrm{IL}-10^{+}$cells in the indicated populations. e Experimental outline for panels ( $\left.\mathbf{f}-\mathbf{i}\right)$. $\mathbf{f}$ Kinetic analysis of numbers of each mononuclear phagocyte subset after i.t. instillation of Pam3CSK4, LPS, and CpG. g Representative contour plot of CD16.2 and CD206 expression within CD64+ IM from control (Day 0), and Pam3CSK4-, LPS- and CpG-injected mice 7 days after treatment. $\mathbf{h}$ Kinetic analysis of MHC-II expression within the indicated populations after Pam3CSK4, LPS or CpG treatment. i Numbers of IL-10+ cells within the indicated subpopulations 7 days after treatment. $\mathbf{d}, \mathbf{f}, \mathbf{h}, \mathbf{i}$ Data show mean \pm s.e.m., as well as individual mice in (d, i), and are pooled from 2 independent experiments $(\mathbf{d}, n=9 ; \mathbf{f}, \mathbf{h}, n=5-6 /$ time point; $\mathbf{i}, n=3-5)$. $P$-values were calculated using $\mathbf{d}$, i non-parametric Mann-Whitney tests for pairwise comparisons or $\mathbf{f}, \mathbf{h}$ two-way ANOVA with Tukey's post hoc tests. ${ }^{\star} P<0.05 ;{ }^{\star \star} P<10^{-2}$; ${ }^{\star \star \star} P<10^{-3}$; ${ }^{\star \star \star \star} /{ }^{0000} P<10^{-4}$; ns, not significant. In $\mathbf{f}$ the empty circles compare numbers of CD206+ IM 3 days after LPS vs. day 0 . Source data are provided as a Source Data file. i.t., intratracheal

of $\mathrm{CD} 64^{+} \mathrm{CD} 16.2^{+}$monocytes. Second, we performed i.v. adoptive transfers of blood donor CD45.1/2+ Ly-6Chi classical and Ly-6Clo patrolling monocytes into naïve $\mathrm{CD} 45.2^{+}$recipient hosts and analyzed the percentages of donor cells in Ly-6Clo patrolling monocytes, CD $64^{+} \mathrm{CD} 16.2^{+}$monocytes and CD206- ${ }^{-}$IM 7 days later (Fig. 7c). Transfer of Ly-6C lo monocytes, unlike that of Ly$6 \mathrm{C}^{\text {hi }}$ monocytes, resulted in a significant increase in the percentage of donor Ly-6Clo monocytes in the lung vasculature as compared to non-transferred mice (Fig. 7d). While donor cells were hardly detectable in $\mathrm{CD}^{+} 4^{+} \mathrm{CD} 16.2^{+}$monocytes, there was a trend towards an increase in percentages of donor cells in $\mathrm{CD}_{206}^{-} \mathrm{IM}$ when mice were transferred with Ly-6Clo monocytes, but not with Ly-6Chi monocytes (Fig. 7d).

In order to boost IM expansion, we injected $\mathrm{CpG}$, which resulted in a drastic increase in numbers of $\mathrm{CD} 64^{+} \mathrm{CD} 16.2^{+}$cells (Fig. 5f, g). To our surprise, we were not able to assess the chimerism of CpG-injected WT:Nr4a1 ${ }^{-/-} \mathrm{BM}$ mixed chimeras since they died following $\mathrm{CpG}$ administration, suggesting that NR4A1-dependent BM cells were needed to counteract CpGinduced toxicity (Fig. 7e). Of note, we reported a similar death in CpG-injected $I l 10^{-1-}$ mice ${ }^{18}$, supporting the hypothesis that CpG-induced IL-10-producing IM counteract the toxicity of CpG, and, as a corollary, that NR4A1-dependent cells could be precursors of $\mathrm{CpG}$-induced IM. We injected WT, $\mathrm{Nr}_{4} \mathrm{al}^{-/-}$, $\mathrm{Ccr} 2^{-/-}$, and $\mathrm{Il10^{-/- }}$ mice with $\mathrm{CpG}$ and found that, while WT and $C \mathrm{cr} 2^{-/-}$mice all survived after $\mathrm{CpG}$ injection, survival of $\mathrm{Nr} 4 a 1^{-/-}$and $I l 10^{-/-}$mice was significantly decreased as compared to WT mice, and all surviving mice had to be euthanized after 3-6 days due to excessive weight loss (Fig. 7e). This was associated with an altered profile of $\mathrm{CD} 64^{+} \mathrm{IM}$ on the Ly-6C/CD64 plot and the abnormal presence of $\mathrm{Ly}-6 \mathrm{C}^{+} \mathrm{CD} 64^{+}$ inflammatory monocytes in $\mathrm{Nr}_{4} \mathrm{ar} 1^{-/-}$and $\mathrm{Il10}^{-/-}$mice 3 days after CpG (Fig. 7f).

Together, our data support the notion that, at steady-state, Ly$6 \mathrm{C}^{\text {lo }}$ patrolling monocytes can enter the lung tissue to differentiate into $\mathrm{CD}^{2} 06^{-} \mathrm{IM}$ via an intermediate CD $64^{+} \mathrm{CD} 16.2^{+}$state. After CpG, NR4A1 and IL-10 are needed to counteract $\mathrm{CpG}$ toxicity, probably through the expansion of IL-10-producing macrophages from NR4A1-dependent precursors.

\section{Discussion}

In this study, we investigated the diversity of lung tissue CD64expressing mononuclear phagocytes in mice. Our study describes the existence of two main IM subpopulations in naive adult mice, confirming recent findings ${ }^{22}$, and further expands our knowledge about their half-life, self-maintenance potential, and localization at steady-state, as well as their stimulus-dependent regulation in an inflammatory context. In addition, we uncover that Ly-6Clo patrolling monocytes can transition into extravasating $\mathrm{CD} 4^{+} \mathrm{CD} 16.2^{+}$monocytes to give rise to $\mathrm{CD} 206^{-} \mathrm{IM}$.

We have provided RNA-seq-based evidence that the CD206 ${ }^{+}$ IM subpopulation was similar to the published Lyve- $1^{\text {hi }}$ MHC$\mathrm{II}^{\mathrm{lo} 22}$ and the IM1/IM2 ${ }^{21}$ subpopulations, whereas CD206- IM profiles were similar to those of Lyve- $1^{\text {lo }}$ MHC-IIhi22 and IM3 ${ }^{21}$. Like Lyve- $1^{\text {hi MHC-II }}{ }^{\text {lo }}$ IM $^{22}$, CD206 ${ }^{+}$IM were larger and comprised more IL-10-expressing cells. Even though Lyve-1 was also shown to be uniquely expressed by CD206 ${ }^{+}$IM (Fig. 1h) and IM1/IM2 ${ }^{21}$, the levels of Lyve-1 staining were, however, lower in CD206 ${ }^{+}$IM as compared to Lyve-1 ${ }^{\text {hi MHC-II }}{ }^{\text {lo }}$ IM $^{22}$, suggesting that CD206 may be more appropriate to discriminate IM subpopulations, at least in the lung. Conversely, CD206- IM, like Lyve- $1^{\text {lo }} \mathrm{MHC}-\mathrm{II}^{\text {hi }} \mathrm{IM}^{22}$, were smaller and negative for Lyve-1, and expressed higher levels of CX3CR1 and MHC-II than the other subset. Of note, two populations of tissue $\mathrm{CD}^{+} 4^{+}$macrophages have also been described in human lungs, one of them expressing CD206, similarly to CD206 ${ }^{+}$IM in mice 22 .

Regarding the maintenance of IM subsets in adults, our and others' approaches all converged to the fact that IM subsets were slowly replaced by monocytes in adult mice ${ }^{21,22}$. Here, we also showed that CD206 ${ }^{+}$IM were able to proliferate and had an increased self-maintenance potential as compared to $\mathrm{CD}^{206^{-}}$ $\mathrm{IM}^{21}$. Under the experimental conditions tested, we found that the half-life of $\mathrm{CD}^{2} 06^{-}$and CD206 ${ }^{+}$IM subsets were estimated at 9 and 12 months, respectively.

Quantitative data about the precise localization of lung IM (subpopulations) remained scarce and controversial ${ }^{12,21,22}$. In this regard, we originally observed $\mathrm{F} 4 / 80^{+} \mathrm{CD} 11 \mathrm{c}^{-} \mathrm{IM}$ in the alveolar parenchyma ${ }^{12}$. Rodero et al. also described CX3CR ${ }^{\text {hi }}$ IM in alveolar areas ${ }^{37}$, while Gibbings et al. proposed later that IM were uniquely located in the bronchial interstitium ${ }^{21}$. More recently, Chakarov et al. looked at peribronchial IM subsets and proposed that Lyve- $1^{\text {lo }}$ MHC-II ${ }^{\text {hi }}$ and Lyve- $1^{\text {hi MHC-II }}{ }^{\text {lo }}$ IM were mainly associated with nerves and blood vessels, respectively ${ }^{22}$. To assess whether IM subsets populated distinct niches in the lung, we evaluated their preferential localization with respect to their bronchial vs. alveolar interstitial abundance. Our study identifies both alveolar and bronchial parenchymal IM, with $\mathrm{CD}^{206^{+}}$and $\mathrm{CD}^{2} 06^{-}$IM preferentially found in the bronchial and the alveolar interstitium, respectively, and bronchial CD206 ${ }^{+}$ IM located in the vicinity of blood vessels. Additional computerbased quantitative analyses together with cutting-edge multicolor imaging technologies will likely help to unambiguously address the precise localization of lung IM subsets, at steady-state and over the course of inflammatory responses.

Importantly, IM dichotomy was also observed at the functional level. We showed that bronchial CD206 ${ }^{+}$IM were endowed with a superior ability to secrete immunoregulatory cytokines, 

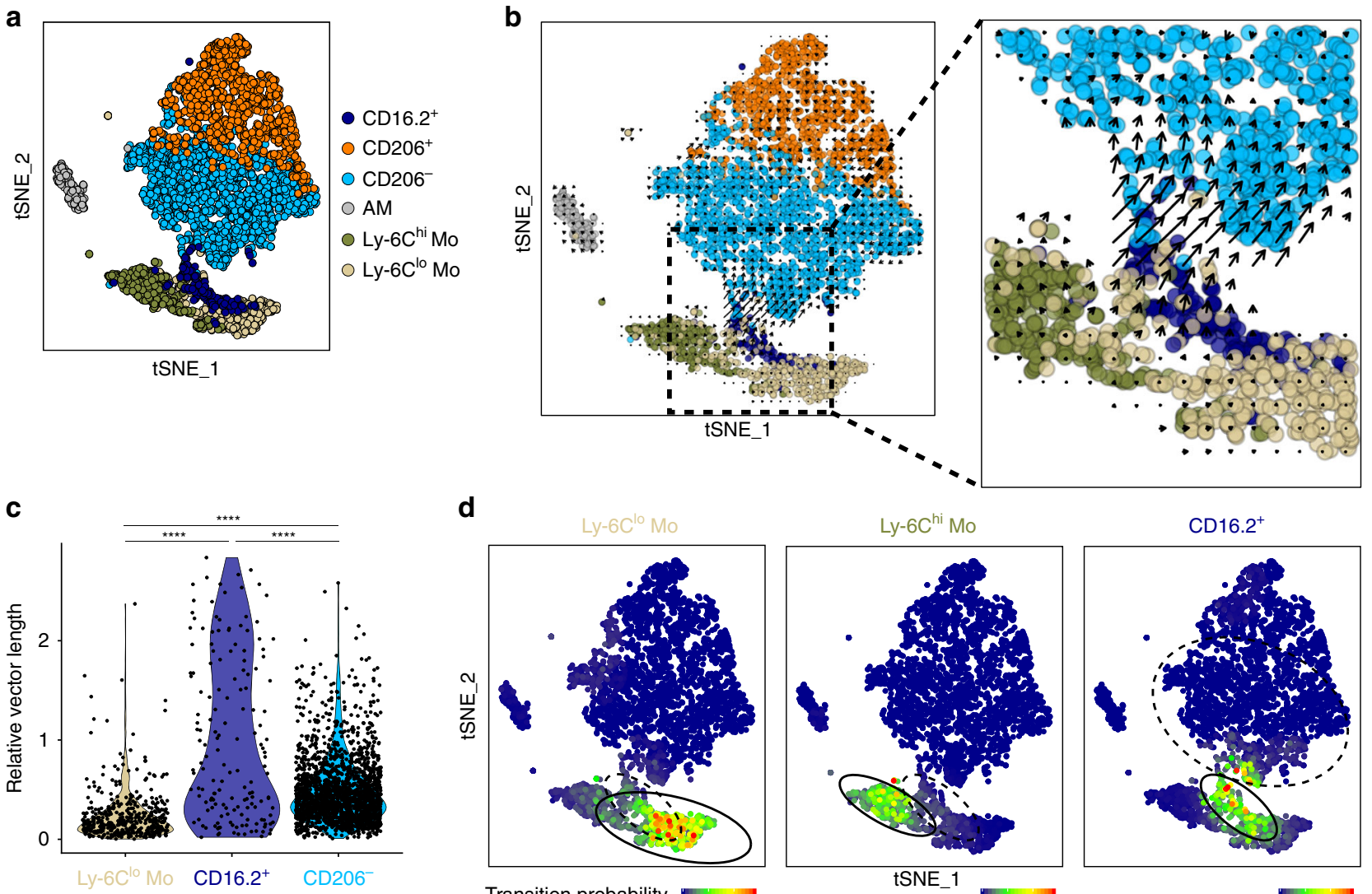

d
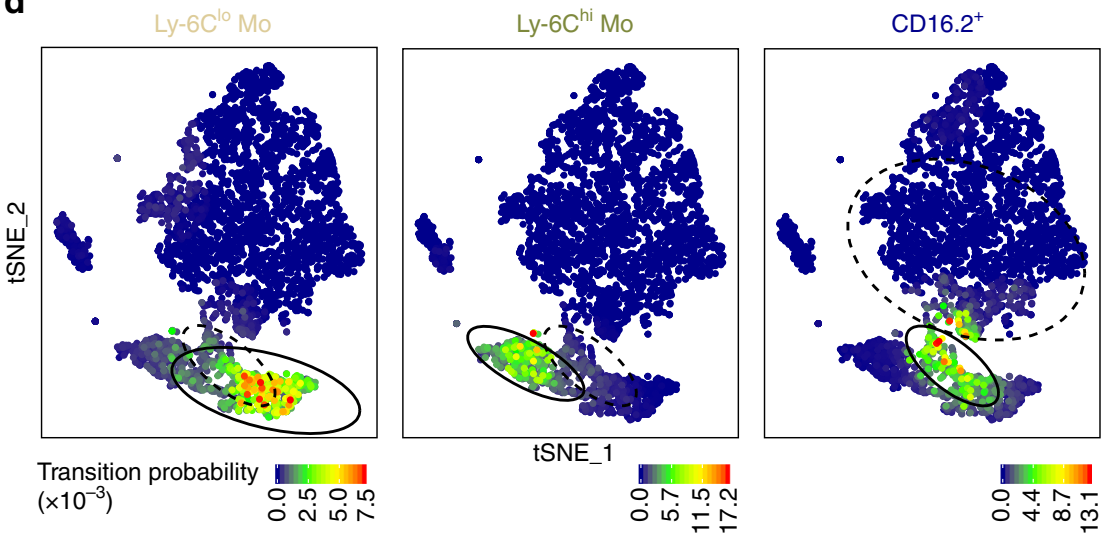

e
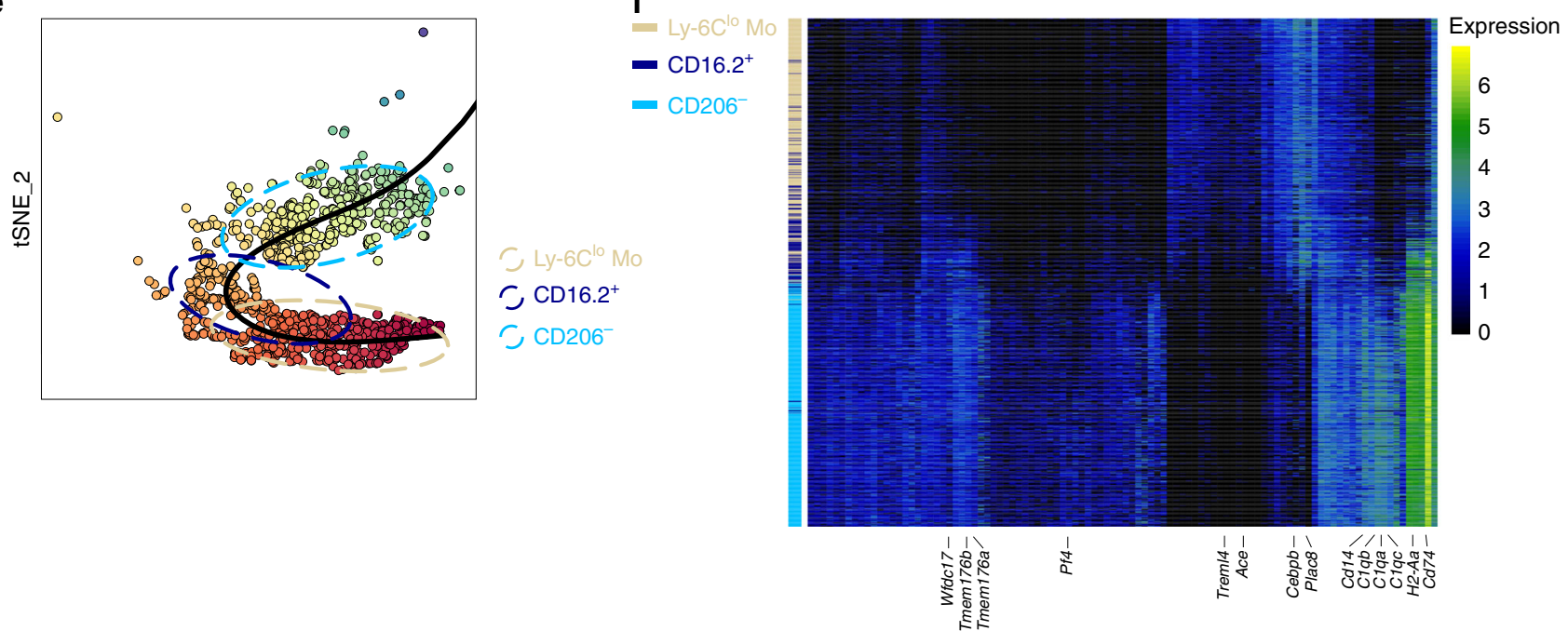

Fig. 6 RNA velocity and trajectory analyses of lung monocyte and IM subpopulations in steady-state C57BL/6 mice. a t-SNE plot depicting the merged scRNA-seq data of lung CD64-expressing cells (see Fig. 1c), Ly-6Clo patrolling monocytes (see Supplementary Fig. 9) and Ly-6Chi classical monocytes (see Supplementary Fig. 12). b Prevalent patterns of RNA velocities substantiated by arrows and visualized on the same t-SNE plot as shown in (a). Right panel shows a higher magnification of the area depicted by a black dashed line in the left panel. (see single cell velocities in Supplementary Fig. 13). c Violin plot showing quantification of single cell relative 2D velocities in the indicated cell (sub)populations, as presented in Supplementary Fig. 13. d Visualization of single-step transition probabilities from Ly-6Clo patrolling monocytes (left), Ly-6Chi classical monocytes (middle) or CD64 ${ }^{+}$CD16.2 ${ }^{+}$monocytes (right) to neighboring cells. Ellipses represent $95 \%$ confidence. e, f Slingshot analysis of Ly- $6 \mathrm{C}^{\mathrm{lo}}$ patrolling monocytes, CD $64+\mathrm{CD} 16.2^{+}$monocytes, and neighboring CD206- IM. e Suggested pseudo-time trajectory from Ly-6Clo patrolling monocytes to CD206- IM. Ellipses represent $80 \%$ confidence. f Heatmap depicting gene expression profiles of Ly-6Clo patrolling monocytes, CD64+CD16.2+ monocytes, and neighboring CD206- IM ordered according to Slingshot pseudo-time trajectory. Left color bars indicate annotation by cell type 
a

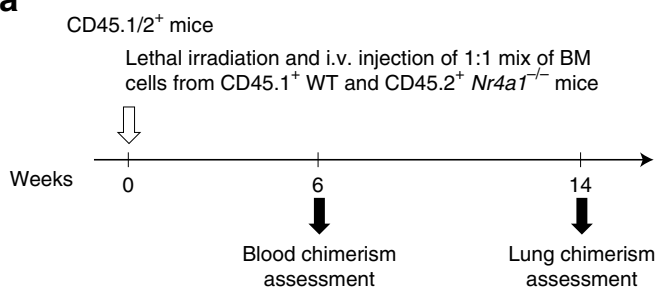

C

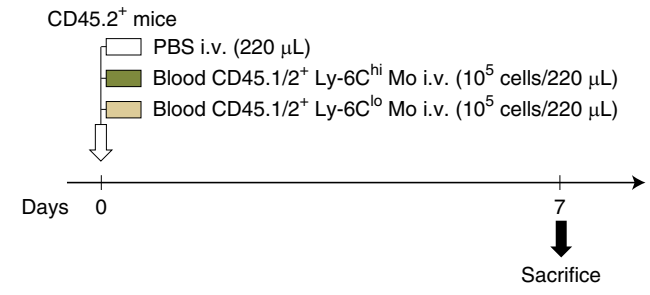

e

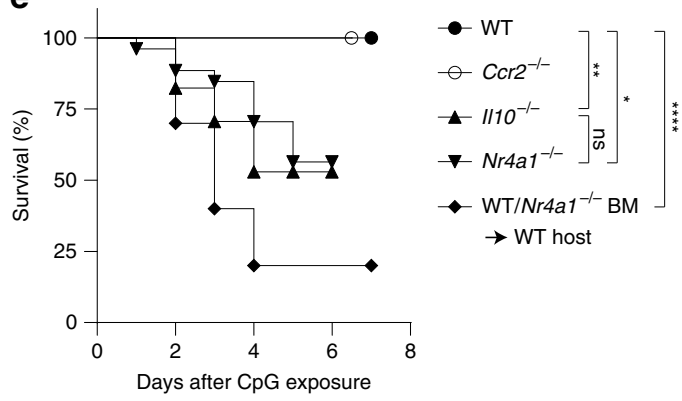

b
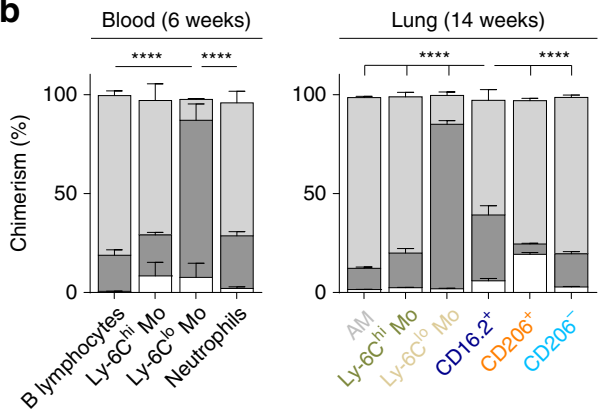

$\square \mathrm{CD} 45.2^{+} \mathrm{Nr}^{-121^{-1}}$

$\mathrm{CD} 45.1^{+} \mathrm{WT}$

CD45.1/2 host

d
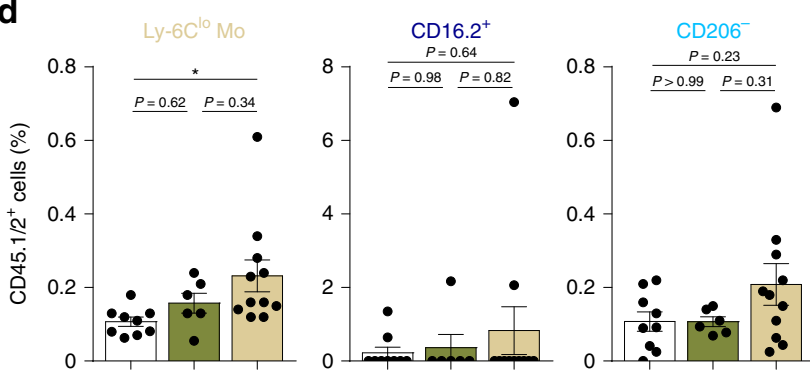

$\mathbf{f}$

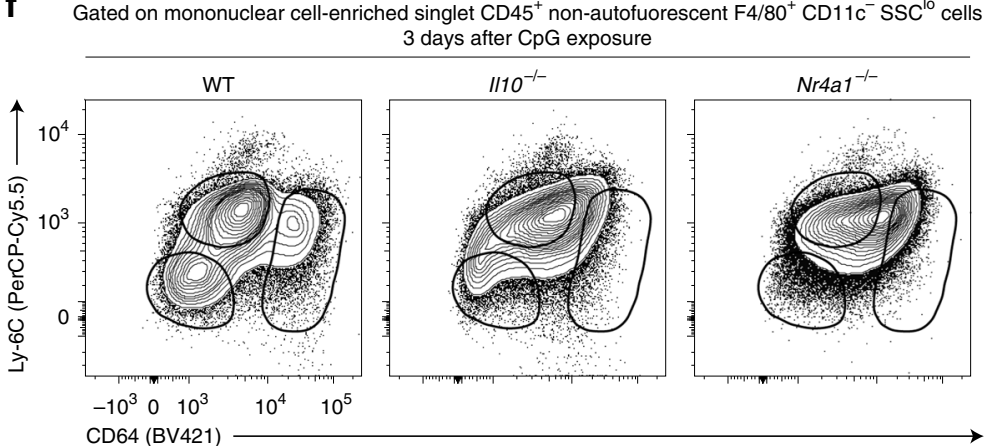

Fig. 7 Patrolling monocyte-derived NR4A1-dependent CD16.2+ monocytes are local precursors of CD206- IM. a Experimental outline for experiments using mixed BM competitive chimeras shown in (b). b Percentage of BM chimerism and radio-resistance of the indicated populations. $\mathbf{c}$ Experimental outline for (d). d Percentages of CD45.1/2+ cells within the indicated cell populations. e Survival (\% of live animals) were monitored at the indicated mice after CpG treatment. $P$-values are versus CpG-injected WT mice. $\mathbf{f}$ Representative contour plot of Ly-6C and CD64, gated on singlet mononuclear cellenriched $\mathrm{CD}_{4}{ }^{+}$non-autofluorescent SSCloF4/80+CD11c ${ }^{-}$cells (see Fig. 1a). Data are representative of 1 of 4 mice analyzed, each giving similar patterns. Data in $\mathbf{b}$, d shown mean \pm s.e.m., as well as individual mice in (d), and are pooled from (b) 2 or (d) 3 independent experiments (b, $n=3$ [blood] or 7 [lung]; d, $n=6-11$ /group). e Data were pooled from 2-4 independent experiments ( $n=10-26 /$ group). $P$-values were calculated using $\mathbf{b}$ a one-way ANOVA followed by Tukey's post hoc tests, $\mathbf{d}$ non-parametric Mann-Whitney tests for pairwise comparisons or e Mantel-Cox tests. ${ }^{\star} P<0.05$; ${ }^{\star \star} P<10^{-2}$; ${ }_{\star \star \star \star \star} P<10^{-4}$; ns, not significant. i.v., intravenous

including IL-10, consistent with the hypothesis that they may largely account for the reported homeostatic functions of steadystate $\mathrm{IM}^{12,15}$. CD206 ${ }^{+} \mathrm{IM}$ were also suggested to be implicated in response to wounding, which fits well with their reported role in regulating damage-induced inflammation and fibrosis ${ }^{22}$. Conversely, CD206- ${ }^{-}$IM exhibited a typical antigen-presenting cell profile and have been shown to regulate $\mathrm{T}$ cell-related processes ${ }^{22}$.

Kinetic analyses of changes in IM subsets after in vivo exposure to 3 different TLR ligands revealed a complex picture of the IM compartment during inflammation. Overall, CD64 ${ }^{+} \mathrm{CD} 16.2^{+}$and $\mathrm{CD}^{2} 6^{-}$IM were more affected by the treatments than CD206 ${ }^{+}$ IM. It is also interesting to note that LPS and CpG, which have been shown to expand IM by CCR2-dependent and independent mechanisms ${ }^{18}$, respectively, exhibited very distinct dynamics over time. LPS amplified the 3 IM subsets at day 3 but mostly CD206 ${ }^{-}$ IM at day 7, while CpG robustly amplified the $\mathrm{CD} 64^{+} \mathrm{CD} 16.2^{+}$ compartment, among which most cells expressed IL-10, followed by an increase in CD206- IM peaking at day 14. Moreover, there was a drop in MHC-II expression observed within $\mathrm{CD}_{206}^{-}$cells after each of the treatments, which likely reflects an influx of recruited $\mathrm{MHC}-\mathrm{II}^{\mathrm{lo}}$ monocytes into this gate, some of which giving rise later to $\mathrm{MHC}-\mathrm{II}^{\text {hi }} \mathrm{CD}^{2} 06^{-}$cells (day 14). Functionally, these data suggest that $\mathrm{CpG}$-elicited IM-derived protection against allergic asthma ${ }^{18}$ may be largely attributed to IL-10-producing $\mathrm{CD}^{+} 4^{+} \mathrm{CD} 16.2^{+}$cells rather than $\mathrm{CD}^{206^{-}}$or $\mathrm{CD}^{206}{ }^{+} \mathrm{IM}$.

Besides IM subsets, we identified a discrete population of NR4A1dependent $\mathrm{CD} 4^{+} \mathrm{CD} 16.2^{+}$monocytes that was mainly located in the alveolar area of the lung. Such monocytes were distinct from the previously described tissue-associated Ly-6Chi monocytes ${ }^{18,27}$ by their phenotype $\left(\mathrm{CD} 64^{+} \mathrm{Ly}-6 \mathrm{C}^{\mathrm{lo}} \mathrm{CX} 3 \mathrm{CR} 1^{\mathrm{hi}} \mathrm{CD} 16.2^{+}\right.$vs. CD64lo Ly6C ${ }^{\text {hi }} \mathrm{CX} 3 \mathrm{CR} 1^{\mathrm{lo}} \mathrm{CD} 16.2^{-}$for Ly-6Chi monocytes) and their dependency on NR4A1. Using transgenic reporter mice, Rodero et al. previously detected a population of CX3CR $1^{\text {hi }}$ monocytes located at the interface between lung capillaries and alveoli ${ }^{37}$. Interestingly, such monocytes were phenotypically similar to $\mathrm{CD} 64^{+} \mathrm{CD} 16.2^{+}$ monocytes and exhibited motility patterns that were distinct from those of intravascular Ly- $6 \mathrm{C}^{\text {lo }}$ patrolling monocytes but similar to those of alveolar CX3CR $1^{\text {hi }} \mathrm{IM}^{37}$, consistent with our findings. 
The localization, phenotype, transcriptomic profile and RNA velocity analysis of $\mathrm{CD} 64^{+} \mathrm{CD} 16.2^{+}$monocytes, together with the mixed chimeras and adoptive transfer experiments supported the notion that $\mathrm{CD} 64^{+} \mathrm{CD} 16.2^{+}$monocytes arose from intravascular patrolling Ly-6 $\mathrm{Clo}$ monocytes and represented an extravascular transition state towards $\mathrm{CD}^{206^{-}}$IM. First, $\mathrm{CD}^{+} 4^{+} \mathrm{CD} 16.2^{+}$monocytes and $\mathrm{CD} 206^{-} \mathrm{IM}$ preferentially populated a similar micro-anatomical niche, i.e. the alveolar parenchyma ${ }^{37}$. Second, CD $64^{+} \mathrm{CD} 16.2^{+}$monocytes shared similarities with patrolling Ly-6Clo monocytes (i.e., surface phenotype, half-life, dependence on NR4A1). Third, despite these similarities, we observed that $\mathrm{CD} 64^{+} \mathrm{CD} 16.2^{+}$monocytes were partly extravascular and, unlike Ly-6Clo monocytes, expressed CD64 and significant levels of IL-10, a functional hallmark of lung $\mathrm{IM}^{12,15,18}$. Fourth, $\mathrm{CD} 64^{+} \mathrm{CD} 16.2^{+}$monocytes upregulated many transcripts that were also highly expressed by $\mathrm{CD}^{206^{-}}$IM, suggestive of a tissue-specific imprinting. Fifth, RNA velocity analysis revealed a highly dynamic transition state of these cells, characterized by a high probability to rapidly differentiate into $\mathrm{CD} 206^{-} \mathrm{IM}$ on a timescale of hours ${ }^{34}$. Sixth, reconstitution of $\mathrm{CD} 64^{+} \mathrm{CD} 16.2^{+}$ monocytes after lethal irradiation was NR4A1-dependent, at least partially, further supporting that they derive from Ly- $6 \mathrm{C}^{\text {lo }}$ patrolling monocytes. Seventh, some Ly-6C ${ }^{\text {lo }}$ patrolling monocytes that were transferred i.v. were found within the pool of CD206- IM 7 days later. Finally, IM expansion induced by CpG was impaired in patrolling monocyte-deficient $\mathrm{Nr}_{4} \mathrm{a1}^{-/-}$ mice, and $\mathrm{CpG}$ instillation, which was well tolerated in WT or $\mathrm{Ccr} 2^{-1-}$ mice, induced death in $\mathrm{Nr}_{4} \mathrm{al}^{-/-}$, a phenotype also observed in $I l 10^{-/}$mice in which IM are not able to produce IL-10, a cytokine needed to counteract CpG toxicity.

While we have identified $\mathrm{CD} 64^{+} \mathrm{CD} 16.2^{+}$monocytes as readily mobilizable precursors for $\mathrm{CD}^{2} 6^{-} \mathrm{IM}$, our data do not rule out the possibility that they may also give rise to $\mathrm{CD} 206^{+} \mathrm{IM}$, and that classical Ly- $6 \mathrm{C}^{\text {hi }}$ monocytes could also differentiate into CD206 ${ }^{-}$ or $\mathrm{CD} 206^{+} \mathrm{IM}$, consistent with the idea that different precursors could compete for the same niche $e^{5-8}$. Of note, numbers of IM subsets are not substantially affected in $\mathrm{Ccr}^{-/-}$or $\mathrm{Nr}^{-1 \mathrm{a}^{-/-}}$ mice, whose numbers of blood classical Ly- $6 \mathrm{C}^{\mathrm{hi}}$ and patrolling Ly$6 \mathrm{C}^{\mathrm{lo}}$ monocytes are impaired, respectively ${ }^{30,31}$. In light of our data, it is tempting to speculate that both Ly- $6 \mathrm{C}^{\mathrm{hi}}$ and Ly-6Clo monocytes represent potentially redundant sources for lung IM. As a corollary, Ly-6C $\mathrm{C}^{\mathrm{o}}$ and Ly-6 $\mathrm{C}^{\text {hi }}$ monocytes would represent the main source of IM subsets in $\mathrm{Ccr} 2^{-1-}$ and $\mathrm{Nr}_{4 a 1^{-1-}}$ mice where the respective competitors are impaired.

This is an exciting time in macrophage research. With regards to lung tissue macrophages, future efforts should be made to investigate the transcriptional programs and tissue-instructive signals tailoring the identity of IM subsets, as well as the biological functions of IM subsets in health and diseases. Novel transgenic tools allowing the selective tracking, modulation, and depletion of such cells will be instrumental in addressing these questions, and will likely have important consequences for the elaboration of therapeutic approaches for lung chronic inflammatory diseases which would target one specific IM subset while sparing the other.

\section{Methods}

Mice. C57BL/6J WT mice were purchased from Janvier Laboratories. Ccr2 $2^{-/-}$, $\mathrm{Nr}_{4 a 1^{-/-}}, \mathrm{IllO}^{-/-}$, WT CD45.1 and Cx3cr1 GFP/GFP (B6.129P-Cx3cr1 $1^{\text {tmlLitt/J) mice }}$ under the C57BL/6J background were purchased from the Jackson Laboratory (Cat. \# 004999, 006187, 002251, 002014 and 005582, respectively). CD45.1/2+ were obtained by crossing $\mathrm{CD} 45.1^{+}$with $\mathrm{CD} 45.2^{+}$mice. IL-10- $\beta$-lactamase reporter (ITIB) C57BL/6 mice were described elsewhere ${ }^{33}$. Cx3cr1 ${ }^{\text {CreERT2 }}$ Rosa26-LSL-YFP C57BL/6 mice were kindly provided by Pr. G. Boeckxstaens (KU Leuven, Belgium). Cx3cr1 ${ }^{\text {CreERT2 }}$ mice were originally obtained from Steffen Jung, Weizmann Institute of Science ${ }^{29}$, and Rosa26-LSL-YFP mice were originally obtained from Daniel
Richardson, University College London ${ }^{38}$. All mice were housed and bred in institutional SPF facilities at the GIGA Institute (Liège University, Belgium) and were used at 7-11 weeks of age, unless otherwise indicated. $\mathrm{Cx} 3 \mathrm{cr})^{\mathrm{CreERT} 2}$. Rosa26$L S L-Y F P$ mice were bred and maintained at KU Leuven (Belgium). All animals and experimental procedures, except experiments involving Cx3cr1 ${ }^{\text {CreERT2 }}$.Rosa26-LSLYFP mice were reviewed and approved by the Institutional Animal Care and Use Committee of the University of Liège (Belgium). Fate-mapping experiments were approved by the Animal Care and Animal Experiments Committee of the Medical Faculty of the KU Leuven (Belgium). The Guide for the Care and Use of Laboratory Animals, prepared by the Institute of Laboratory Animal Resources, National Research Council, and published by the National Academy Press, as well as European and local legislations, were followed carefully.

Reagents and antibodies. A complete list of the reagents and antibodies used in this study can be found in Supplementary Table 3.

Lung single cell isolation, stainings, and flow cytometry. To obtain single-lungcell suspensions, lungs were extensively perfused with $3 \mathrm{ml}$ of HBSS (Lonza) through the right ventricle, cut into small pieces with razor blades, and digested for $1 \mathrm{~h}$ at $37^{\circ} \mathrm{C}$ in HBSS containing $5 \% \mathrm{v} / \mathrm{v}$ of FBS (Gibco), $1 \mathrm{mg} \cdot \mathrm{ml}^{-1}$ collagenase A (Roche) and $0.05 \mathrm{mg} \cdot \mathrm{ml}^{-1}$ DNase I (Roche). After $45 \mathrm{~min}$ of digestion, the suspension was flushed using a $18 \mathrm{G}$ needle to dissociate aggregates. PBS (Gibco) containing $10 \mathrm{mM}$ of EDTA (Merck Millipore) was added to stop the digestion process. The suspension was then filtered and enriched in mononuclear cells by using a density gradient (Percoll from GE Healthcare) and harvesting cells from the 1.080:1.038 $\mathrm{g} \mathrm{ml}^{-1}$ interface.

Staining reactions were performed at $4{ }^{\circ} \mathrm{C}$ in FACS buffer (PBS containing 50\% $\mathrm{v} / \mathrm{v}$ of Brilliant Stain Buffer [BD Pharmingen], $2.5 \mathrm{mg} \mathrm{ml}^{-1}$ of BSA [Sigma], $0.5 \mathrm{mg}$ $\mathrm{ml}^{-1}$ of sodium azide [Acros Organics]) with $2 \% \mathrm{v} / \mathrm{v}$ of Fc block (BD Pharmingen) to reduce non-specific binding. Cell phenotyping was performed on a

FACSLSRFortessa (BD Biosciences). Cell sorting was performed on a FACSAriaIII (BD Biosciences) using the nozzle 85 at a rate allowing minimum $85 \%$ of efficiency. The purity of sorted cells was consistently above $95 \%$ for every sample. Results were analyzed using FlowJo V10 (Tree Star Inc.). Normalized MFI represents MFI for each sample with the mean of control cells MFI subtracted.

Anti-mouse CD68, Lamp-1 and Ki-67 intracellular stainings were performed by resuspending extracellular-stained cells in $500 \mu$ l of Fixation Buffer (Biolegend) for $40 \mathrm{~min}$ at room temperature (RT). Cells were then washed twice with $1 \mathrm{ml}$ of permeabilization buffer (Thermo Fisher Scientific). Cells were stained for intracellular protein in $100 \mu$ l of fixation/permeabilization buffer (Thermo Fisher Scientific) with $2 \% \mathrm{v} / \mathrm{v}$ of Fc block (BD Pharmingen) for $30 \mathrm{~min}$ at RT.

For experiments involving ex vivo cultures and morphology assessment, cell suspensions were enriched by a magnetic-activated cell sorting (MACS) using antimouse CD11b microbeads (Miltenyi Biotec) according to manufacturer's protocol, instead of the density gradient method. The negative fraction was also collected for the staining of AM.

Lung cell numbers were counted after whole lung digestion and mononuclear cell enrichment. The numbers of cells within each population were determined according to the gating strategy shown in Fig. 1a.

Lung single cell preparation for scRNA-seq. Lung tissue CD64-expressing cells were FACS-sorted as singlet mononuclear cell-enriched $\mathrm{CD}_{4} 5^{+}$non-autofluorescent $\mathrm{SSC}^{\mathrm{lo}} \mathrm{F} 4 / 80^{+} \mathrm{CD} 11 \mathrm{c}^{-} \mathrm{Ly}-6 \mathrm{C}^{\mathrm{lo}} \mathrm{CD} 64^{+}$cells as shown in Fig. 1a. In the first replicate experiment, IM were isolated from lung single-cell suspensions pooled from three 10-week-old C57BL/6 female WT mice. In parallel, AM were FACS-sorted as singlet mononuclear cell-renriched $\mathrm{CD}_{4} 5^{+} \mathrm{CD} 11 \mathrm{c}^{+}$autoflurorescent cells and were spiked in as controls at a ratio of 1:10. Such experiment was performed at KU Leuven (Belgium), while the second replicate was performed by independent experimenters through an independent pipeline using a pool of 6-month-old C57BL/6 female WT mice that were maintained in a different animal facility at the GIGA Institute (Liège University, Belgium). The 10x Genomics platform (Single Cell 3' Solution) was used for scRNA-seq, and sequencing was performed at the Genomics Platform of the GIGA Institute (Liège University, Belgium) for both experiments. For scRNA-seq analysis of lung Ly- $6 \mathrm{C}^{\mathrm{lo}}$ and Ly- $6 \mathrm{C}^{\mathrm{hi}}$ monocytes, lung $\mathrm{CD} 45^{+} \mathrm{F} 4 / 80^{+} \mathrm{CD} 11 \mathrm{c}^{-} \mathrm{Ly}-$

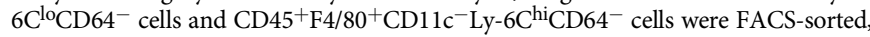
respectively. For each sample, an aliquot of Trypan blue-treated cells was examined under the microscope for counting, viability and aggregate assessment following FACS sorting. Viability was above $80 \%$ for all samples and no aggregate were observed. Cell preparations were centrifuged at $1503 \mathrm{RCF}$ for $4 \mathrm{~min}$ and pellets were resuspended in calcium- and magnesium-free PBS containing $0.4 \mathrm{mg} \mathrm{ml}^{-1}$ of UltraPure BSA (Thermo Fisher Scientific).

Sequencing libraries were generated by using the Chromium ${ }^{\text {nut }}$ Single Cell 3 Reagent Kits v2 (10× Genomics) following the manufacturer's instructions. GEMRT was performed in a Veriti ${ }^{\odot}$ 96-Well Thermal Cycler (Thermo Fisher Scientific). After RT, GEMs were broken and the cDNAs were cleaned up with DynaBeads MyOne Silane beads (Thermo Fisher Scientific). cDNAs were then amplified in a Veriti $^{\odot}$ 96-Well Thermal Cycler. According to the expected cell recovery (based on a $60 \%$ recovery of total loaded cells), number of amplification cycles was set to 12 . Amplified cDNA products were cleaned up using SPRIselect Reagent kit (Beckman 
Coulter), after what purified cDNAs were quality controlled and quantified using an Agilent High Sensitivity DNA Kit (Agilent) on a 2100 Bioanalyser (Agilent). Illumina's P5, P7 and Read2 primers, as well as Sample Index were then added to generate sequencing libraries following Chromium ${ }^{\mathrm{mi}}$ Single Cell 3' Reagent Kits v2 protocol. Steps were as follows: (1) enzymatic fragmentation, end repair and Atailing, (2) Double Sided Size Selection using SPRIselect reagent, (3) adaptor ligation, (4) post ligation cleanup with SPRIselect reagent, (5) Sample index PCR (number of cycles set to 14) and (6) Double Sided Size Selection using SPRIselect reagent. The barcoded sequencing libraries were quality controlled using an Agilent High Sensitivity DNA kit on a 2100 Bioanalyser and quantified by quantitative PCR (KAPA Biosystems Library Quantification Kit for Illumina platforms).

Sequencing libraries were loaded at $1.4 \mathrm{pM}$ on an Illumina NextSeq500 with NextSeq 500/550 Mid Output v2 kit (150 cycles) (Illumina) using the following read lengths: $26 \mathrm{bp}$ for Read1 (16 bp Barcode +10 bp Randomer), 8 bp for Sample Index and 58 bp for Read2. Cell Ranger software (v1.2.0) (10x Genomics) was used to demultiplex Illumina BCL files to FASTQ files (cellranger mkfastq), to perform alignment (to mouse GRCm $38 / \mathrm{mm} 10$ genome), filtering, UMI counting and to produce gene-barcode matrices (cellranger count).

Analysis of scRNA-seq samples. Analyses used R bioconductor ${ }^{39}$ (version 3.4.2.), and the R package Seurat ${ }^{40}$ (version 2.3.4).

Briefly, for analysis of lung CD64-expressing mononuclear phagocytes, we first performed a quality control analysis and selected cells for further analysis in each replicate. Cells with a minimum of 200 and a maximum of 2500 detected genes were included, and cells with more than $5 \%$ of mitochondrial genes were excluded (Supplementary Fig. 2). In addition, only genes detected in at least 3 cells were included. Gene counts were normalized by using a global-scaling method that normalizes the gene expression measurements for each cell by the total expression, multiplies it by 10,000 and log-transforms the result. The FindVariableGenes function was used to calculate highly variable genes with the x.low.cutoff, x.high. cutoff and y.cutoff parameters set to $0.0125,3$, and 0.5 , respectively. Cell-cell variation in the number of detected unique molecular identifiers (UMI) was regressed out using the ScaleData function. To analyze both replicates simultaneously, we used the MergeSeurat function, creating a new object with the resulting combined data matrices and appending a given identifier to each cell name depending on which original object the cell comes from. Linear dimensional reduction was performed on the scaled data using the RunPCA function. To identify the number of statistically significant principal components (PC) to include for subsequent analyses, we used the JackStraw function, which implements a resampling test inspired by the JackStraw procedure ${ }^{2}$. Alternatively, we used the PCElbowPlot function, looked at a plot of the standard deviations of the PC and determined our cutoff where there is an elbow on the graph, located at $\sim$ PC 8 . PC $1: 8$ were thus used in the subsequent analyses. We also performed analyses including lower and higher numbers of PC (1:6 to 1:12) and did not find any substantial differences in the results obtained.

The cells were clustered via the FindClusters function. Several cluster resolutions were tested, and the resolution of 0.2 was chosen, since higher resolutions created additional subdivisions or clusters containing singlets, which were considered not biologically relevant. To visualize the data, non-linear dimensional reduction was used, and $t$-SNE plots were created by using the RunTSNE function, with the number of dimensions to use set to 8 (PC 1:8). To eliminate a potential contamination with cells outside the MPS, data were subset using the SubsetData function in order to only keep cell clusters expressing detectable levels of the Csflr gene.

Differential expression (DE) analysis between clusters was performed using the FindMarkers function, which uses a likelihood ratio test based on zero-inflated data to identify positive and negative markers of a single cluster compared to some or all other clusters. Only DE genes with an adjusted $P$-value $<10^{-2}$ were retained. To compare Cluster 3 (i.e., AM) with Clusters 1, 2, and 4 (i.e., tissue CD64-expressing cells), lists of the significantly DE genes between Cluster 3 and Clusters 1, 2, and 4 were generated. To compare the clusters of lung tissue CD64-expressing cells (i.e., Clusters 1, 2 and 4) with each other, lists of the significantly DE genes between Cluster 1 and Clusters 2 and 4, Cluster 2 and Clusters 1 and 4, or Cluster 4 and Clusters 1 and 2 were generated. Based on these lists of DE genes, Gene ontology analyses were performed using the Gene Ontology Consortium website (http://geneontology.org/) referring to the GO Ontology database released on 2018/12/01.

To visualize specific marker expression, the DotPlot function was used to show average expression of the genes and percentage of cells expressing the indicated genes within each cluster. Alternatively, the FeaturePlot or DoHeatmap functions were used to show specific gene expression across single cells.

For subsequent analyses, a similar procedure as described above was used with minor adaptations. For analysis of lung Ly- $6 C^{\text {lo }}$ and Ly- $6 C^{\text {hi }}$ monocytes, cells with a maximum of 3,000 detected genes were included, PC 1:8 were used and a resolution of 0.1 is shown for the cell clustering depicted in Supplementary Figs. 9d and 12. To compare Ly- $6 \mathrm{C}^{\text {lo }}$ patrolling and lung $\mathrm{CD} 64^{+} \mathrm{CD} 16.2^{+}$monocytes, data of original Cluster 4 (i.e., CD $64^{+} \mathrm{CD} 16.2^{+}$monocytes) were subset from the dataset of lung CD64-expressing mononuclear phagocytes and merged with the data of Ly$6 \mathrm{C}^{\mathrm{lo}}$ monocytes. PC 1:8 and a resolution of 0.3 were used for the cell clustering and subsequent analyses depicted in Fig. 6, Supplementary Figs. 13 and 14a, b.
For the graphical representation of RNA velocities, a Seurat object encompassing lung CD64-expressing mononuclear phagocytes, Ly-6Clo patrolling monocytes and Ly- $6 \mathrm{C}^{\text {hi }}$ classical monocytes was created and the corresponding $t$ SNE plot (PC 1:8) was used as shown in Fig. 6, Supplementary Figs. 13 and 14a, b.

Transcriptomic comparison of lung IM subsets. To compare CD206- and $\mathrm{CD}^{206^{+}}{ }^{\mathrm{IM}}$ subsets with Lyve ${ }^{\text {hi MHCII }}{ }^{\mathrm{lo}}$ and $\mathrm{Lyve}^{\mathrm{lo}} \mathrm{MHCII}^{\mathrm{hi}}$ IM subsets reported in Chakarov et al. ${ }^{22}$, we generated CD206 ${ }^{-}$and CD206 ${ }^{+} \mathrm{IM}$ signatures (i.e., upregulated genes in $\mathrm{CD}_{206^{-1+}}$ vs. CD206 $6^{+/-} \mathrm{IM}$, respectively) based on our scRNA-seq data. Briefly, in order to be comparable between two analyses, numbers of genes within the $\mathrm{CD}^{206^{-}}$and $\mathrm{CD}^{206^{+}}$IM signatures should be similar to those of Lyve ${ }^{\text {hi MHCII }}{ }^{\text {lo }}$ and Lyve $1^{\text {lo MHCII }}{ }^{\text {hi }}$ IM signatures. Using the FindMarkers function (Seurat package ${ }^{41}$ ), we selected genes with a log fold change threshold of 0.1 , and that are expressed in more than $10 \%$ of cells. The Venn diagram was generated with a publicly available online tool (http://bioinformatics.psb.ugent.be/webtools/Venn/). Gene Set Enrichment Analysis (GSEA) was performed to analyze enrichment of published Lyve ${ }^{\text {hi MHCII }}{ }^{\text {lo }}$ and Lyve ${ }^{\text {lo MHCII }}{ }^{\text {hi }}$ IM signatures ${ }^{22}$ in $\mathrm{CD}^{206}{ }^{-}$and CD206+ IM (see below).

To compare CD206- ${ }^{-}$and CD206 ${ }^{+}$IM subsets with the IM1, IM2, and IM3 populations reported in Gibbings et al. ${ }^{21}$, data of expression counts were downloaded from Gene Expression Omnibus database (accession GSE94135) and analyzed with DESeq 2 package ${ }^{42}$ for differential expression analysis, hierarchical clustering, and PCA analysis. As a high similarity was found between IM1 and IM2 signatures, we generated an IM1\&IM2 shared signature (634 genes) and an IM3 signature (97 genes), which were used as gene sets in the GSEA analysis described below.

For GSEA, in order to analyze enrichment of published signatures in our scRNAseq data, the normalized counts were used as expression datasets in GSEA. Briefly, genes were ranked based on their expression in $\mathrm{CD}_{206^{+}}$and CD206 ${ }^{-}$macrophages by Signal2Noise method. Normalized Enrichment Score (NES), FDR and nominal $p$-value were calculated with 100 permutations between samples from different phenotypes.

Cytologic examination. Cytologic examination of FACS-sorted populations was performed on cytospin preparations stained with Hemacolor ${ }^{\circledR}$ (Merck, Cat. 111955 111956, 111957). Sections were examined with a FSX100 microscope (Olympus) and size comparisons were performed using Image J software (NIH).

In vivo labeling of vascular leukocytes. Lightly isoflurane-anesthetized C57BL/6 J WT mice were injected i.v. with $300 \mu \mathrm{L}$ of PBS, or with $0.5 \mu \mathrm{g}$ of mouse APCconjugated anti-mouse CD45.2 antibodies in $300 \mu \mathrm{l}$ PBS. The antibodies were allowed to circulate for $3 \mathrm{~min}$ prior to euthanasia in order to label all leukocytes present in the vascular compartment. Lungs were harvested without perfusion and were processed for flow cytometry analysis.

Assessment of phagocytic activity. Lightly isoflurane-anesthetized C57BL/6J WT mice were injected i.t. or i.v. with $6 \times 10^{8}$ pHrodo $^{\mathrm{mm}}$ Green E. coli BioParticules ${ }^{\mathrm{Tm}}$ (Thermo Fisher Scientific, Cat. P35366) in $100 \mu \mathrm{l}$ and $200 \mu \mathrm{l}$ of PBS respectively. Lungs were harvested $3 \mathrm{~h}$ later for cell isolation, staining and flow cytometry analysis.

Fate-mapping of lung $\mathbf{C X} \mathbf{3} \mathbf{C R} \mathbf{1}^{+}$cells. The induction of Cre recombinase to trace CX3CR1 ${ }^{+}$cells was performed as described elsewhere ${ }^{43}$. Briefly, 4 week-old CX3 $\mathrm{cr} 1^{\text {CreERT2 }}$.Rosa26-LSL-YFP mice were treated three times subcutaneously with $4 \mathrm{mg}$ TAM (Sigma, Cat. T5648) per $30 \mathrm{~g}$ body weight dissolved in corn oil (Sigma, Cat. C8267), $48 \mathrm{~h}$ apart. The mice were sacrificed after 2, 9, 28, and 52 weeks, and lungs were processed for flow cytometry analysis. Lungs from untreated CX3cr1 ${ }^{\text {CreERT2 }}$.Rosa26-LSL-YFP mice were used as negative control.

Immunostainings and confocal microscopy analyses. Freshly collected lungs from C57BL/6J WT and $\mathrm{C} x 3 \mathrm{cr} 1^{\mathrm{GFP} / \mathrm{GFP}}$ mice were embedded and frozen in OCT compound (Q Path Freeze gel, VWR), and then cut in $10 \mu \mathrm{m}$ cryosections. Tissue sections were then fixed in $4 \%$ paraformaldehyde for $10 \mathrm{~min}$ at RT, permeabilized in $0.5 \% \mathrm{v} / \mathrm{v}$ of Triton-X100 (Sigma) for $2 \mathrm{~min}$ at RT and blocked in PBS containing $2 \% \mathrm{v} / \mathrm{v}$ of BSA and $2 \%$ of goat serum (Sigma) for $1 \mathrm{~h}$ at RT. Sections were first stained with a rat anti-mouse CD68 (dilution 1:100) for $2 \mathrm{~h}$ at RT, then with an AF568-conjugated goat anti-rat antibody (dilution 1:1000) for $2 \mathrm{~h}$ at RT. For samples isolated from $C \times 3 c r 1^{\mathrm{GFP} / \mathrm{GFP}}$ mice, sections were then stained overnight at $4{ }^{\circ} \mathrm{C}$ with AF488-conjugated antibodies against GFP (dilution 1:200) and AF647conjugated antibodies against CD16.2 (1:20), CD206 (1:100) or MHC-II (1:50). For samples isolated from WT mice, sections were then stained overnight at $4{ }^{\circ} \mathrm{C}$ with AF647-conjugated antibodies against CD31 (1:200) or Tubb3 (1:100), and AF488conjugated antibodies against CD16.2, CD206 or MHC-II. For assessment of MHC-II and CD206 co-expression, WT sections were simultaneously stained with antibodies against MHC-II and CD206. Cell nuclei were counterstained with 4,6diamidino-2-phenylindole (DAPI, Biolegend) for $5 \mathrm{~min}$ at RT. Sections were mounted with Prolong Diamond Antifade Mountant (Thermo Fisher) and stored for at least $5 \mathrm{~h}$ at RT. Samples were rinsed 3 times in PBS between each of the above-mentioned steps. Images were acquired on a Zeiss LSM 880 confocal microscope (Zeiss) and analyzed using the ZEN 2.3 software (Zeiss). 
Spatial distribution was quantified by analyzing, for each sample, 5 or 10 fields (magnification $\times 20$ ) containing at least one $\mathrm{CX} 3 \mathrm{CR} 1{ }^{+} \mathrm{CD} 68^{+}$cell in the peribronchial/perivascular area or the alveolar parenchyma, respectively. For each sample, the mean of the numbers of $\mathrm{CX} 3 \mathrm{CR} 1{ }^{+} \mathrm{CD} 68^{+} \mathrm{CD} 206^{+}, \mathrm{CX} 3 \mathrm{CR} 1{ }^{+} \mathrm{CD} 68^{+}$ MHC- $\mathrm{II}^{+}$and $\mathrm{CX} 3 \mathrm{CR} 1^{+} \mathrm{CD} 68^{+} \mathrm{CD} 16.2^{+}$cells per field was used to calculate the spatial distribution of these cells. Double positivity for CD206 and MHC-II was quantified by analyzing, for each sample, 5 fields (magnification $\times 20$ ) in peribronchial/perivascular and alveolar parenchymal areas containing at least one $\mathrm{CD} 8^{+} \mathrm{CD} 206^{+}$or $\mathrm{CD} 68^{+} \mathrm{MHC}-\mathrm{II}^{+}$cell. For each sample, the numbers of $\mathrm{CD} 68^{+}$ $\mathrm{CD}^{206}{ }^{+}, \mathrm{CD} 8^{+} \mathrm{MHC}-\mathrm{II}^{+}$cells and $\mathrm{CD} 68^{+} \mathrm{CD} 206^{+} \mathrm{MHC}^{-\mathrm{II}^{+}}$cells were used to calculate the percentage of CD206/MHC-II double positive cells.

Proteome profiler assay. $\mathrm{CD} 206^{-}$and $\mathrm{CD} 206^{+} \mathrm{IM}$ subpopulations were FACSsorted from naive C57BL/6J WT mice and $5 \times 10^{4}$ cells were cultured in an Fbottom 96-well plate during $16 \mathrm{~h}$ in $100 \mu \mathrm{l}$ of RPMI with L-glutamine (Lonza) supplemented with $10 \% \mathrm{v} / \mathrm{v}$ FBS, $1 \% \mathrm{v} / \mathrm{v}$ MEM non-essential amino acids (Gibco), $1 \mathrm{mM}$ sodium pyruvate (GE Healtcare), $50 \mathrm{U} \mathrm{ml}^{-1}$ penicillin/streptomycin (Gibco), $0.05 \mathrm{mM} \mathrm{2-mercaptoethanol} \mathrm{(Gibco),} \mathrm{with} \mathrm{or} \mathrm{without} 10 \mathrm{ng} \mathrm{ml}^{-1}$ of LPS (Sigma). For each experimental condition, supernatants were tested for the presence of cytokines and chemokines using a proteome profiler mouse XL cytokine array (R\&D Systems), according to manufacturer instructions. Results were visualized using an ImageQuant LAS 4000 (GE Healthcare) and analyzed using Image) software. Results are expressed as Z-scores for each analyte ([individual value - analyte mean] per analyte standard deviation).

Assessment of IL-10 expression in ITIB mice. To assess IL-10 expression using IL-10- $\beta$-lactamase reporter ITIB mice ${ }^{33}$, lung cells from IL-10- $\beta$-lactamase reporter ITIB and control WT mice were resuspended in a CCF4-AM (Thermo Fisher Scientific, Cat. K1028)-containing solution supplemented with probenecid (Thermo Fisher Scientific, Cat. P36400) prepared according to manufacturer's instructions, and incubated $90 \mathrm{~min}$ at $29^{\circ} \mathrm{C}$. CCF4-loaded cells were then classically stained and analyzed by flow cytometry. CCF4-loaded cells from C57BL/6J WT mice were used as negative controls.

Estimations of RNA velocities in single cells. RNA velocities in single cells were estimated with RNA velocity (http://velocyto.org) ${ }^{34}$. Briefly, spliced and nonspliced transcripts counts were calculated from CellRanger output using Python command line tool velocyto with default run10x subcommand. Genes with minimum average expression of 0.5 (for spliced transcripts) or 0.05 (for non-spliced transcripts) within at least one cell cluster were filtered before velocity estimation. RNA velocities were estimated using 20 k-nearest neighbors (NN) in slope calculating smoothing, and fit quantile of 0.02 . RNA velocities were then visualized using correlation-based transition probability matrix within the kNN graph, with same cluster labels and embedding as in Fig. 6 a.

To compare RNA velocity across subsets of Ly- $6 \mathrm{C}^{\mathrm{lo}}$ patrolling monocytes, $\mathrm{CD}^{+} 4^{+} \mathrm{CD} 16.2^{+}$monocytes and $\mathrm{CD} 206^{-} \mathrm{IM}$, the relative distance from the cell position in the 2D-tSNE plot to the projected position (i.e., effective length of arrows displayed in Supplementary Fig. 13b) was used to illustrate the RNA velocity of each cell.

Cell fate decision estimation. Cell fate decision was represented by RNA-velocitybased single-step transition probabilities from starting cells to neighboring cells. To illustrate cell fate decision probabilities of all cells in a given subset (i.e., the starting subset), the total transition probability (TP $n$ ) to neighboring cells $n$ was calculated as the sum of all transition probabilities (TPin) of single cells in the given subset (containing $j$ cells), and corrected by the number of cells:

$$
\operatorname{TP} n=\frac{\sum_{i=1}^{j} \mathrm{TP} i n}{j}
$$

For illustration, transition possibility of each cell position was indicated by a color gradient while an ellipse marked the starting subset of interest with $95 \%$ confidence on the cell positions in the subset.

Trajectory analyses. For trajectory analyses, the previously published package Slingshot ${ }^{35}$ was used. Briefly, Slingshot uses pre-existing clustering information to calculate development trajectory and pseudo-time of each cell in the development trajectory. To analyze the differentiation trajectory from Ly- $6 \mathrm{C}^{\mathrm{lo}}$ patrolling monocytes to $\mathrm{CD} 206^{-}$IM subpopulation, we reanalyzed the data sets shown in Fig. 6a with Seurat using higher resolution (i.e., 2.5), and the 5 clusters covering Ly-6Clo patrolling monocytes, $\mathrm{CD} 64^{+} \mathrm{CD} 16.2^{+}$monocytes, and neighboring CD206- IM were used for Slingshot analysis. For clarity purposes, the original $t$-SNE embedding of Fig. 6a was retained to illustrate cell positions in Fig. $6 \mathrm{e}$ and the ellipses with $80 \%$ confidence were drawn to illustrate their cluster belonging shown in Fig. 6a using the same colors. To find the temporally expressed genes through trajectory, we used the method suggested in the Slingshot package to regress genes on the pseudo-time variable using a generaladditive model. Expression of the top 100 genes on $p$-value was showed in a heatmap across all cells in selected subsets.
White blood cell isolation. To obtain single-blood-cell suspensions, blood was collected in a tube containing $500 \mu \mathrm{L}$ of PBS (Gibco) containing $100 \mathrm{mM}$ of EDTA (Merck Millipore) and red blood cells were lysed by adding distilled water containing $150 \mathrm{mM}$ of ammonium chlorure (VWR) and $10 \mathrm{mM}$ of potassium bicarbonate (Sigma). Cells were then centrifuged, resuspended in FACS buffer and stained as described for lung cells in the respective section above.

Bone marrow mixed chimeras. Eighteen-week-old CD45.1/2+WT mice were lethally irradiated with two doses of $6 \mathrm{~Gy} 3 \mathrm{~h}$ apart. Two hours after the second irradiation, these mice were injected i.v. with $2 \times 10^{6} \mathrm{BM}$ cells consisting of a 1:1 mix of BM cells obtained from CD45.1+ WT and CD45.2+ Nr4a1-/- mice. From the day before irradiation, mice were treated for 4 weeks with $0.05 \mathrm{mg} \cdot \mathrm{ml}^{-1}$ of enrofloxacin (Baytril, Bayer). Chimerism was assessed by flow cytometry in the blood and the lung 6 and 14 weeks after irradiation, respectively. In the blood, B lymphocytes, Ly- $6 \mathrm{C}^{\mathrm{lo}}$ monocytes, Ly- $6 \mathrm{C}^{\text {hi }}$ monocytes and neutrophils, were defined as $\mathrm{CD}^{2} 5^{+} \mathrm{CD} 11 \mathrm{~b}^{-} \mathrm{Ly}-6 \mathrm{G}^{-} \mathrm{CD} 19^{+}, \mathrm{CD} 45^{+} \mathrm{CD} 11 \mathrm{~b}^{+} \mathrm{Ly}_{-} 6 \mathrm{G}^{-} \mathrm{CD} 115^{+} \mathrm{Ly}_{-} 6 \mathrm{C}^{-}, \mathrm{CD}^{+} 5^{+}$ CD11b ${ }^{+} \mathrm{Ly}-6 \mathrm{G}^{-} \mathrm{CD} 115^{+} \mathrm{Ly}-6 \mathrm{C}^{+}$and $\mathrm{CD} 45^{+} \mathrm{CD} 11 \mathrm{~b}^{+} \mathrm{Ly}-6 \mathrm{G}^{+}$cells, respectively.

Monocyte adoptive transfers. Blood cells of CD45.1/2+ mice were collected and stained for FACS sorting of Ly- $6 \mathrm{C}^{\text {hi }}$ and Ly- $6 \mathrm{C}^{\mathrm{lo}}$ monocytes, defined as $\mathrm{CD}_{4}{ }^{+} \mathrm{CD} 11 \mathrm{~b}^{+} \mathrm{CD} 115^{+} \mathrm{Ly}-6 \mathrm{C}^{+}$and $\mathrm{CD} 45^{+} \mathrm{CD} 11 \mathrm{~b}^{+} \mathrm{CD} 115^{+} \mathrm{Ly}-6 \mathrm{C}^{+}$cells, respectively. These cells were then transferred to $\mathrm{CD} 45.2^{+}$WT recipient mice by injecting $10^{5} \mathrm{Ly}-6 \mathrm{C}^{\text {hi }}$ or Ly-6 $\mathrm{C}^{\text {lo }}$ monocytes i.v. into each mouse. Lungs were harvested 7 days later for cell isolation, staining and flow cytometry analysis.

Intratracheal instillations of TLR ligands. Lightly isoflurane-anesthetized C57BL/6J WT mice were injected i.t. with Pam3CSK4, LPS or CpG $(25 \mu \mathrm{g}, 10 \mu \mathrm{g}$ and $50 \mu \mathrm{g}$, respectively) in $50 \mu \mathrm{l}$ of PBS. Lungs were harvested $1,3,5,7,14$ or 28 days later for cell isolation, staining and flow cytometry analyses. C57BL/6 WT, $\mathrm{Crr}^{-/-}, \mathrm{Nr}_{\mathrm{aa1}} \mathrm{1}^{-/-}, \mathrm{Ill10^{-/- }}$, and WT:Nr4a1 ${ }^{-/-}$1:1 $\mathrm{BM}$ mixed chimeras were injected i.t. with $50 \mu \mathrm{g}$ of $\mathrm{CpG}$ in $50 \mu \mathrm{l}$ of PBS. The survival of these mice was assessed and lungs from WT, $\mathrm{Nr}_{4} \mathrm{II}^{-/-}$and $\mathrm{IllO}^{-/-}$mice were harvested 3 days later for flow cytometry analysis. ITIB mice were injected i.t. with $50 \mu \mathrm{g}$ of $\mathrm{CpG}$ in $50 \mu \mathrm{l}$ of PBS and their lungs were harvested 7 days later for cell isolation, staining and IL-10 production analysis by flow cytometry.

Statistical analysis. Data from independent experiments were pooled for analysis in each data panel, unless otherwise indicated. Statistical analyses were performed using Prism 7 (GraphPad Software), SAS (version 9.3) and R bioconductor ${ }^{39}$ (version 3.4.2.). Data were presented as mean \pm s.e.m., as well as individual values, unless otherwise indicated. We considered a $P$-value lower than 0.05 as significant. ${ }^{\star} P<0.05 ;{ }^{* *} P<10^{-2},{ }^{* *} P<10^{-3} ;{ }^{* * *} P<10^{-4} ;$ ns, not significant. Details about the statistical tests used can be found in the respective Figure legends. Details about the analysis of scRNA-seq data can be found in the respective sections above.

Reporting summary. Further information on research design is available in the Nature Research Reporting Summary linked to this article.

\section{Data availability}

The scRNA-seq data provided in this manuscript have been deposited in the ArrayExpress database at EMBL-EBI under accession number E-MTAB-7678. The source data underlying Figs. 1f, g, j; 2b, c, f and h; 3c-f; 4b; 5d, f, h and i; and 7b, d, e and Supplementary Figs. $7 \mathrm{c} ; 8$ b, d; 9 b; and 10 are provided as a Source Data file, as mentioned in the respective Figure legends.

Received: 18 February 2019 Accepted: 7 August 2019 Published online: 03 September 2019

\section{References}

1. Epelman, S., Lavine, K. J. \& Randolph, G. J. Origin and functions of tissue macrophages. Immunity 41, 21-35 (2014).

2. Ginhoux, F. \& Guilliams, M. Tissue-resident macrophage ontogeny and homeostasis. Immunity 44, 439-449 (2016).

3. Okabe, Y. \& Medzhitov, R. Tissue biology perspective on macrophages. Nat. Immunol. 17, 9-17 (2016).

4. Lavin, Y. et al. Tissue-resident macrophage enhancer landscapes are shaped by the local microenvironment. Cell 159, 1312-1326 (2014).

5. Guilliams, M. \& Scott, C. L. Does niche competition determine the origin of tissue-resident macrophages? Nat. Rev. Immunol. 17, 451-460 (2017).

6. van de Laar, L. et al. Yolk sac macrophages, fetal liver, and adult monocytes can colonize an empty niche and develop into functional tissue-resident macrophages. Immunity 44, 755-768 (2016)

7. Scott, C. L. et al. Bone marrow-derived monocytes give rise to self-renewing and fully differentiated Kupffer cells. Nat. Commun. 7, 10321 (2016). 
8. Takata, K. et al. Induced-Pluripotent-Stem-Cell-Derived Primitive Macrophages Provide a Platform for Modeling Tissue-Resident Macrophage Differentiation and Function. Immunity 47, 183-198 e6 (2017).

9. Guilliams, M. et al. Alveolar macrophages develop from fetal monocytes that differentiate into long-lived cells in the first week of life via GM-CSF. J. Exp. Med 210, 1977-1992 (2013).

10. Hussell, T. \& Bell, T. J. Alveolar macrophages: plasticity in a tissue-specific context. Nat. Rev. Immunol. 14, 81-93 (2014).

11. Schneider, C. et al. Induction of the nuclear receptor PPAR-gamma by the cytokine GM-CSF is critical for the differentiation of fetal monocytes into alveolar macrophages. Nat. Immunol. 15, 1026-1037 (2014).

12. Bedoret, D. et al. Lung interstitial macrophages alter dendritic cell functions to prevent airway allergy in mice. J. Clin. Invest 119, 3723-3738 (2009).

13. Liegeois, M., Legrand, C., Desmet, C. J., Marichal, T. \& Bureau, F. The interstitial macrophage: a long-neglected piece in the puzzle of lung immunity. Cell Immunol. 330, 91-96 (2018).

14. Schyns, J., Bureau, F. \& Marichal, T. Lung interstitial macrophages: past, present, and future. J. Immunol. Res 2018, 5160794 (2018).

15. Kawano, H. et al. IL-10-producing lung interstitial macrophages prevent neutrophilic asthma. Int Immunol. 28, 489-501 (2016).

16. von Mutius, E. The microbial environment and its influence on asthma prevention in early life. J. Allergy Clin. Immunol. 137, 680-689 (2016).

17. Strachan, D. P. Hay fever, hygiene, and household size. BMJ 299, 1259-1260 (1989).

18. Sabatel, C. et al. Exposure to bacterial CpG DNA protects from airway allergic inflammation by expanding regulatory lung interstitial macrophages. Immunity 46, 457-473 (2017).

19. Hoppstadter, J. et al. Differential cell reaction upon Toll-like receptor 4 and 9 activation in human alveolar and lung interstitial macrophages. Respir. Res 11, 124 (2010).

20. Draijer, C. et al. Human asthma is characterized by more IRF5+ M1 and CD206+ M2 macrophages and less IL-10+ M2-like macrophages around airways compared with healthy airways. J. Allergy Clin. Immunol. 140, 280-283.e3 (2017).

21. Gibbings, S. L. et al. Three unique interstitial macrophages in the murine lung at steady state. Am. J. Respir. Cell Mol. Biol. 57, 66-76 (2017).

22. Chakarov, S. et al. Two distinct interstitial macrophage populations coexist across tissues in specific subtissular niches. Science 363, pii: eaau0964 (2019).

23. Zheng, G. X. et al. Massively parallel digital transcriptional profiling of single cells. Nat. Commun. 8, 14049 (2017).

24. Mesnil, C. et al. Lung-resident eosinophils represent a distinct regulatory eosinophil subset. J. Clin. Invest 126, 3279-3295 (2016).

25. Cohen, M. et al. Lung single-cell signaling interaction map reveals basophil role in macrophage imprinting. Cell 175, 1031-1044 e18 (2018).

26. Scott, C. L. et al. The transcription factor ZEB2 is required to maintain the tissue-specific identities of macrophages. Immunity 49, 312-325 e5 (2018).

27. Jakubzick, C. et al. Minimal differentiation of classical monocytes as they survey steady-state tissues and transport antigen to lymph nodes. Immunity 39, 599-610 (2013).

28. Tan, S. Y. S. \& Krasnow, M. A. Developmental origin of lung macrophage diversity. Development 143, 1318-1327 (2016).

29. Yona, S. et al. Fate mapping reveals origins and dynamics of monocytes and tissue macrophages under homeostasis. Immunity 38, 79-91 (2013).

30. Serbina, N. V. \& Pamer, E. G. Monocyte emigration from bone marrow during bacterial infection requires signals mediated by chemokine receptor CCR2. Nat. Immunol. 7, 311-317 (2006).

31. Hanna, R. N. et al. The transcription factor NR4A1 (Nur77) controls bone marrow differentiation and the survival of Ly6C- monocytes. Nat. Immunol. 12, 778-785 (2011).

32. Garlanda, C., Bottazzi, B., Bastone, A. \& Mantovani, A. Pentraxins at the crossroads between innate immunity, inflammation, matrix deposition, and female fertility. Annu Rev. Immunol. 23, 337-366 (2005).

33. Bouabe, H., Liu, Y., Moser, M., Bosl, M. R. \& Heesemann, J. Novel highly sensitive IL-10-beta-lactamase reporter mouse reveals cells of the innate immune system as a substantial source of IL-10 in vivo. J. Immunol. 187, 3165-3176 (2011).

34. La Manno, G. et al. RNA velocity of single cells. Nature 560, 494-498 (2018).

35. Street, K. et al. Slingshot: cell lineage and pseudotime inference for single-cell transcriptomics. BMC Genom. 19, 477 (2018).

36. Mildner, A. et al. Genomic characterization of murine monocytes reveals $\mathrm{C} /$ EBPbeta transcription factor dependence of Ly6C(-) Cells. Immunity 46, 849-862 e7 (2017).

37. Rodero, M. P. et al. Immune surveillance of the lung by migrating tissue monocytes. eLife 4, e07847 (2015).
38. Srinivas, S. et al. Cre reporter strains produced by targeted insertion of EYFP and ECFP into the ROSA26 locus. BMC Dev. Biol. 1, 4 (2001).

39. Gentleman, R. C. et al. Bioconductor: open software development for computational biology and bioinformatics. Genome Biol. 5, R80 (2004).

40. Macosko, E. Z. et al. Highly Parallel Genome-wide Expression Profiling of Individual Cells Using Nanoliter Droplets. Cell 161, 1202-1214 (2015).

41. Butler, A., Hoffman, P., Smibert, P., Papalexi, E. \& Satija, R. Integrating singlecell transcriptomic data across different conditions, technologies, and species. Nat. Biotechnol. 36, 411-420 (2018).

42. Love, M. I., Huber, W. \& Anders, S. Moderated estimation of fold change and dispersion for RNA-seq data with DESeq2. Genome Biol. 15, 550 (2014).

43. De Schepper, S. et al. Self-maintaining gut macrophages are essential for intestinal homeostasis. Cell 175, 400-415 e13 (2018).

\section{Acknowledgements}

We thank all members of the Laboratories of Cellular and Molecular Immunology and Immunophysiology (GIGA Institute) for discussions; Michel Georges, Laurence Fievez and Catherine Sabatel for their precious help and advices; Sandra Ormenese, Raafat Stefan and Jean-Jacques Goval from the GIGA Flow Cytometry and Cell Imaging Platform;

Pierre Drion and all staff members from the GIGA Mouse facility and Transgenics Platform; Chantal Humblet and staff members from the Immunohistology Platform; Benoit Charloteaux, Manon Deckers, Latifa Karim and members from the GIGA Genomics Platform; Cédric François, Pauline Maréchal, Raja Fares and Ilham Sbai for their excellent technical and administrative support; the GIGA Genomics Platform and the VIB Single Cell Accelerator program for supporting the $10 \mathrm{X}$ genomics platforms. F.B. is supported by the $\mathrm{F}$. R.S.-FNRS for the FRFS-WELBIO under grant CR-2012S-01R and by an Excellence Of Science (EOS) program from the F.R.S-FNRS and FWO. T.M. is a Research Associate of the F.R.S.-FNRS and is supported by an Incentive Grant for Scientific Research of the F.R.S.FNRS (F.4508.18), by the FRFS-WELBIO under grant CR-2017s-04, by the Acteria Foundation and by an ERC Starting Grant (ERC StG 2018 IM-ID: 801823).

\section{Author contributions}

T.M. conceived the project. J.S., S.D.S., S.C., D.P., F.G., G.B., F.B. and T.M. were involved in experimental design. J.S. realized most experiments with the help of C.Ru. and C. Ra., S.D.S. and S.C. Q.B., D.P. and T.M. performed the bioinformatic analyses of scRNA-seq data. S.D.S. and G.B. helped with fate-mapping experiments involving C $x 3$ cr $1^{\text {CreERT2 }}$.Rosa26-LSL-YFP mice. F.F. helped with statistical analyses. J.S. compiled the data and prepared the figures with the help of Q.B. T.M. secured funding. T.M. wrote the manuscript with the help of J.S. All authors provided feedback on the manuscript.

\section{Additional information}

Supplementary Information accompanies this paper at https://doi.org/10.1038/s41467019-11843-0.

Competing interests: The authors declare no competing interests.

Reprints and permission information is available online at http://npg.nature.com/ reprintsandpermissions/

Peer review information: Nature Communications thanks Rory Bowden and other, anonymous, reviewers for their contributions to the peer review of this work.

Publisher's note: Springer Nature remains neutral with regard to jurisdictional claims in published maps and institutional affiliations.

Open Access This article is licensed under a Creative Commons Attribution 4.0 International License, which permits use, sharing, adaptation, distribution and reproduction in any medium or format, as long as you give appropriate credit to the original author(s) and the source, provide a link to the Creative Commons license, and indicate if changes were made. The images or other third party material in this article are included in the article's Creative Commons license, unless indicated otherwise in a credit line to the material. If material is not included in the article's Creative Commons license and your intended use is not permitted by statutory regulation or exceeds the permitted use, you will need to obtain permission directly from the copyright holder. To view a copy of this license, visit http://creativecommons.org/licenses/by/4.0/.

(c) The Author(s) 2019 